San Jose State University

SJSU ScholarWorks

Master's Theses

Master's Theses and Graduate Research

1992

\title{
An exploratory study of the characteristics and effects of relevance in persuasive messages for deterrence of female adolescent smoking
}

Robert Dewis

San Jose State University

Follow this and additional works at: https://scholarworks.sjsu.edu/etd_theses

\section{Recommended Citation}

Dewis, Robert, "An exploratory study of the characteristics and effects of relevance in persuasive messages for deterrence of female adolescent smoking" (1992). Master's Theses. 386.

DOI: https://doi.org/10.31979/etd.fvvj-6t46

https://scholarworks.sjsu.edu/etd_theses/386

This Thesis is brought to you for free and open access by the Master's Theses and Graduate Research at SJSU ScholarWorks. It has been accepted for inclusion in Master's Theses by an authorized administrator of SJSU ScholarWorks. For more information, please contact scholarworks@sjsu.edu. 


\section{INFORMATION TO USERS}

This manuscript has been reproduced from the microfilm master. UMI films the text directly from the original or copy submitted. Thus, some thesis and dissertation copies are in typewriter face, while others may be from any type of computer printer.

The quality of this reproduction is dependent upon the quality of the copy submitted. Broken or indistinct print, colored or poor quality illustrations and photographs, print bleedthrough, substandard margins, and improper alignment can adversely affect reproduction.

In the unlikely event that the author did not send UMI a complete manuscript and there are missing pages, these will be noted. Also, if unauthorized copyright material had to be removed, a note will indicate the deletion.

Oversize materials (e.g., maps, drawings, charts) are reproduced by sectioning the original, beginning at the upper left-hand corner and continuing from left to right in equal sections with small overlaps. Each original is also photographed in one exposure and is included in reduced form at the back of the book.

Photographs included in the original manuscript have been reproduced xerographically in this copy. Higher quality $6^{\prime \prime} \times 9 "$ black and white photographic prints are available for any photographs or illustrations appearing in this copy for an additional charge. Contact UMI directly to order.

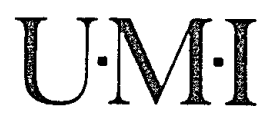

University Microfilms International

A Bell \& Howell Information Company 

Order Number 1950080

An exploratory study of the characteristics and effects of relevance in persuasive messages for deterrence of female adolescent smoking

Dewis, Robert, M.A.

San Jose State University, 1992

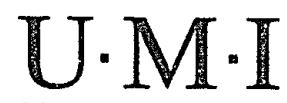





\title{
AN EXPLORATORY STUDY OF THE CHARACTERISTICS AND EFFECTS OF RELEVANCE IN PERSUASIVE MESSAGES FOR DETERRENCE OF FEMALE ADOLESCENT SMOKING
}

\author{
A Thesis \\ Presented to \\ The Faculty of the Department of Communication Studies \\ San Jose State University
}

In Partial Fulfillment of the Requirements for the Degree

Master of Arts

By

Robert Dewis

August, 1992 
APPROVED FOR THE DEPARTMENT OF COMMUNICATION STUDIES

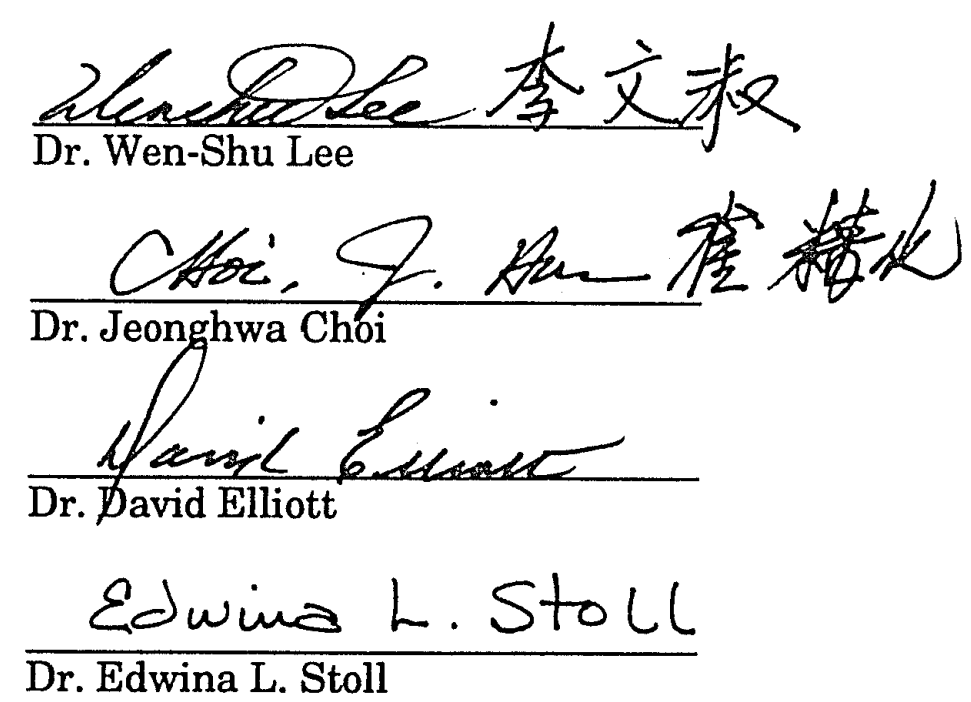

Dr. Edwina L. Stroll

APPROVED FOR THE UNIVERSITY

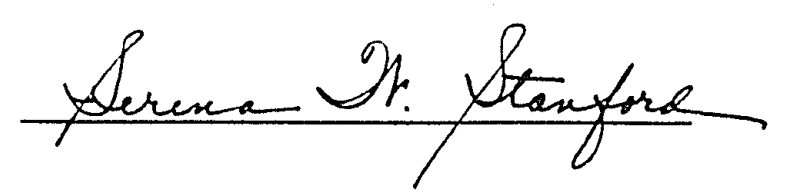




\begin{abstract}
AN EXPLORATORY STUDY OF

THE CHARACTERISTICS AND EFFECTS OF RELEVANCE

IN PERSUASIVE MESSAGES FOR DETERRENCE OF

FEMALE ADOLESCENT SMOKING
\end{abstract}

By Robert Dewis

This study investigates perceived message relevance in processing persuasive messages. Its primary focus was to investigate whether individuals might perceive greater relevance in messages created by others who are similar in demographic and experiential characteristics than in messages created by others who differ in experiential characteristics.

One videotaped "don't smoke" PSA (public service announcement) was created by each of two groups of high school students: female adolescent cigarette smokers, and female adolescent nonsmokers. The PSAs were shown to groups of junior high school students $(\underline{N}=206)$ who responded to a questionnaire.

Embodied in the research were exploratory correlations between relevance and effectiveness; risk-taking orientation and cigarette smoking; and risk-taking, perceived relevance, and perceived effectiveness. Perceived relevance and risk-taking proved to be powerful predictors of perceived effectiveness; perceived relevance positively, and risk-taking orientation negatively.

Implications of this research to persuasive communication and field research are discussed. 


\section{ACKNOWLEDGEMENTS}

I thank Wen-Shu Lee, my advisor, who supported my effort to do socially meaningful research. I also thank Jeonghwa Choi, David Elliott, and Edwina Stoll, my committee members, each of whom provided their unique talents to support and encourage me.

I am grateful to Ray Ramsey, Linda Elliott Rios, and Cathy Williams, without whom the creation and involvement of the PSA production groups would not have been possible.

I am grateful to the faculty and staff of the Department of Communication Studies, San Jose State University for their ideas and support. I thank Jack Ray for encouraging me to apply to the teaching internship program, where I discovered the challenge of teaching communication. I thank Trish Marinas and Vicky Rodriguez for their positive spirit and good humor.

I thank Donna Stasio of De Anza College for her review of the thesis, and for her thoughtful suggestions.

I thank Mia Hoglund, Pamela Kreiser, and Susan Taylor, my fellow graduate students, who have been supportive friends from the beginning.

I thank Kristin, Dannielle, Melanie, and Michelle for their energy, enthusiasm, and commitment.

And, finally, I thank all of the students who participated in this research. They are the ones we try to reach, the ones who have so much to offer, and the ones to whom this thesis is dedicated. 


\section{TABLE OF CONTENTS}

Page

ACKNOWLEDGEMENTS . . . . . . . . . . . . . . iv

LIST OF TABLES . . . . . . . . . . . . . . . . . viii

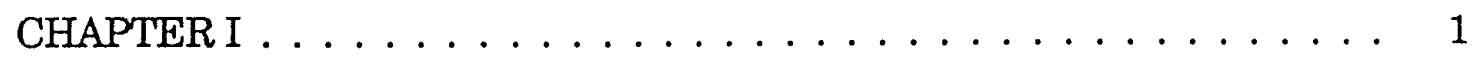

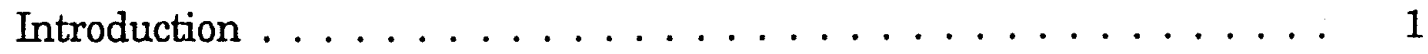

Literature Review I . . . . . . . . . . . . . . . . . . 6

Smoking Statistics, Intervention Frograms, and Women-at-risk . . 6

Smoking Statistics . . . . . . . . . . . . . . 6

Intervention Programs: Success and Failure . . . . . . . . 8

Women-at-risk For Smoking . . . . . . . . . . . . . 10

Literature Review II . . . . . . . . . . . . . . . . . . . . . . 14

Relevance, Involvement, and Persuasion . . . . . . . . . . . 14

Types of Relevance . . . . . . . . . . . . . . . . . . 15

Issues Used in Relevance Research . . . . . . . . . . . . . . . 18

Operationalization and Manipulation of Relevance: Group

Membership and Pre-message Relevance vs. Message-content

Relevance . . . . . . . . . . . . . . . . . . . . 20

Operational Definition . . . . . . . . . . . . . . . . 22

Message Relevance: Message Content and Message Development . 22

Message Content . . . . . . . . . . . . . . . . 22

Relevance and Argument Quality . . . . . . . . . . . . 22

Relevance and Source Credibility . . . . . . . . . . . . . 26 26

Developing Relevant Messages: Media Campaigns/Intervention

Programs . . . . . . . . . . . . . . . . . 27

Summary and Research Questions . . . . . . . . . . . . . 29

CHAPTER II . . . . . . . . . . . . . . . . . . . 33

Methods . . . . . . . . . . . . . . . . . . 33 
Phase 1: The Creation of the PSAs . . . . . . . . . . . 35

Recruiting the PSA Production Team . . . . . . . . . . . 38

Focus Group Meetings . . . . . . . . . . . . . . . . . . 40

Producing and Editing the PSAs . . . . . . . . . . . . 43

Phase 2: Presentation of the PSAs and Survey of Responses . . . . 44

Questionnaire Construction and Face Validity . . . . . . . . . 44

Questionnaire Items . . . . . . . . . . . . . . . 46

Demographics . . . . . . . . . . . . . . . 46

Cigarette smoking experience . . . . . . . . . . 46

Psychosocial variables . . . . . . . . . . . . . . 46

Perceived relevance variable . . . . . . . . . . . . . 47

Perceived effectiveness variable . . . . . . . . . . . 47

Procedure . . . . . . . . . . . . . . . . . 48

CHAPTER III . . . . . . . . . . . . . . . . . . . . 50

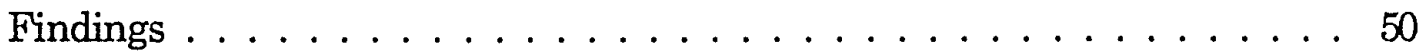

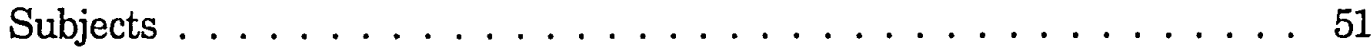

Data Rearrangement . . . . . . . . . . . . . . . . . . 51

Preliminary Findings . . . . . . . . . . . . . . . . . 52

Principal Component Analyses . . . . . . . . . . . . . 52

Reliabilities . . . . . . . . . . . . . . . 57

Composite Variables . . . . . . . . . . . . . . . 58

Research Findings . . . . . . . . . . . . . . . . . . . . 59

Significance of Mean Differences for Select Groups . . . . . . . 59

Analyses of Variance . . . . . . . . . . . . . . . 60

Regression Analyses . . . . . . . . . . . . . . . 65

CHAPTER IV . . . . . . . . . . . . . . . . . . . . 67

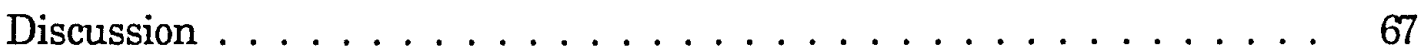

Research Question $1 \ldots \ldots \ldots \ldots$. . . . . . . . . 68 
Research Question $2 \ldots \ldots \ldots \ldots$. . . . . . . . . . 71

Research Question $3 \ldots \ldots \ldots$. . . . . . . . . . . . . 72

Research Question $4 \ldots \ldots \ldots \ldots$. . . . . . . . . . 72

Research Question $5 \ldots \ldots \ldots \ldots \ldots \ldots$. . . . . . . . . 74

Characteristics of the PSAs . . . . . . . . . . . 76

Research with Adolescents in the School Environment . . . . . 77

Conclusion and Recommendations . . . . . . . . . . . . . . 79

REFERENCES . . . . . . . . . . . . . . . . . . . . 82

APPENDIXES . . . . . . . . . . . . . . . . . . . . . . 87

Appendix A - Questionnaire for High School Production Group

Participants . . . . . . . . . . . . . . . . 88

Appendix B - Scripts for Smokers Group and Nonsmokers Group

PSAs . . . . . . . . . . . . . . . . . . 92 


\section{LIST OF TABLES}

TABLES

Page

1. Self-efficacy and Risk-taking Orientation Items. . . . . . . . . 52

2. Factor Analysis of Self-efficacy and Risk-taking Orientation Items . . 53

3. Rotated Factor Matrix of Self-efficacy and Risk-taking Orientation Items . . . . . . . . . . . . . . . . . . 53

4. Perceived Relevance and Effectiveness of Smokers Group PSA Items . 54

5. Factor Analysis of Perceived Relevance and Effectiveness of Smokers Group PSA Items . . . . . . . . . . . . . . . . . 54

6. Rotated Factor Matrix of Perceived Relevance and Effectiveness of Smokers Group PSA Items. . . . . . . . . . . . . . . . 55

7. Perceived Relevance and Effectiveness of Nonsmokers Group PSA Items. . . . . . . . . . . . . . . . . . . . 56

8. Factor Analysis of Perceived Relevance and Effectiveness of Nonsmokers Group PSA Items. . . . . . . . . . . . . . . . 56

9. Rotated Factor Matrix of Perceived Relevance and Effectiveness of Nonsmokers Group PSA Items. . . . . . . . . . . . . . . . . 57

10. Paired t-tests, Perceived Relevance of Smokers Group and Nonsmokers Group PSAs. . . . . . . . . . . . . . . . . . . . . 59

11. Paired t-tests, Perceived Effectiveness of Smokers Group and Nonsmokers Group PSAs. . . . . . . . . . . . . . . . . . 60

12. ANOVA: Risk-taking by Smoking Experience and Gender . . . . . . . 62

13. ANOVA: Risk-taking by Smoking Status and Gender . . . . . . . . 62

14. ANOVA: Perceived Relevance of Nonsmokers Group PSA by Smoking Experience and Gender. . . . . . . . . . . . . . . . 63

15. ANOVA: Perceived Effectiveness of Nonsmokers Group PSA by Smoking Experience and Gender. 
16. ANOVA: Perceived Relevance of Nonsmokers Group PSA by Smoking Status and Gender. . . . . . . . . . . . . . . . . . . . . 65

17. ANOVA: Perceived Effectiveness of Nonsmokers Group PSA by Smoking Status and Gender. . . . . . . . . . . . . . . . 65 


\section{CHAPTER I}

"In the last twenty years, the death rate in women with lung cancer has increased by more than 300 percent in the United States."

Amos \& Chollat-Tarquet, (1990, p. 7)

"You've come a long way, baby."

Virginia Slims cigarette advertisement

\section{Introduction}

Although the numbers are declining, almost 30 percent of the adults in the United States still smoke cigarettes, and smoking continues to be the single, most preventable cause of death (U.S. Department of Health and Human Services [U.S. DHHS], 1989). While cessation programs have had some success in helping adult smokers quit, a significant effort has been made to address the problem where it begins: in adolescence. Because the vast majority of adult smokers began smoking in their early to middle teenage years, a number of programs have been developed to prevent or intercede with the start of cigarette smoking by adolescents.

While these programs have been somewhat successful, both adult and adolescent women have proven to be a particularly high-risk group. They show greater resistance than men both to cessation and prevention efforts. At the same time, tobacco companies advertising cigarette brands such as Virginia Slims promote smoking as a sign of women's liberation. This is especially troubling as medical professionals have seen a dramatic 
increase in the numbers of women with lung cancer, cervical cancer, and birth and pregnancy problems, all believed to be related to cigarette smoking. One group of researchers (Gilchrist, Schinke, \& Nurius, 1989) has identified psychosocial differences between female and male smokers, and believe that current intervention programs are failing to address the needs and concerns that may be particular to female smokers. Other researchers have demonstrated that the motivations of adolescents to experiment with and adopt cigarette smoking are more varied and complex than the typically posited one of peer pressure (Leventhal \& Cleary, 1980). These findings of both psychosocial and motivational differences suggest that current intervention programs may be ignoring important differences between smokers, communicating information to smokers that may be perceived, by some of them, as irrelevant. Messages that are perceived as more relevant by high-risk groups, such as women, could be developed through more attention to their particular concerns, needs, and motivations to smoke, resulting, perhaps, in more effective smoking intervention programs for female smokers.

Perceived message relevance, and the more general construct, involvement, have been studied by communication researchers as important elements in the processing of persuasive messages. While social-judgment involvement theorists (e.g., M. Sherif \& Hovland, 1961) posit that perceived involvement inhibits persuasion, elaboration likelihood model researchers (e.g., Petty \& Cacioppo, 1979) characterize perceived message relevance as a mediating variable, influencing the way 
and extent to which recipients process the content of the message, thereby affecting persuasion. In studies done from either perspective, however, typical operationalizations rely on the manipulation of perceived issue involvement to elicit perceived message relevance, generally ignoring the influence message content may have on perceptions of relevance. It would be valuable to investigate the influence message content has on perceived relevance, as well as the subsequent effect this perception would have on the processing of, and response to, persuasive communication.

Persuasion research investigating relevance as a variable has also been limited by the types of issues typically used in the manipulation of perceived issue relevance. Researchers have generally used questions related to either institutional policies (e.g., Leippe \& Elkin, 1987; Sorrentino, Bobocel, Gitta, Olson, \& Hewitt, 1988; Petty \& Cacioppo, 1979), purchase choices (e.g., Burnkrant \& Unnava, 1989; Homer \& Kahle, 1990; Kardes, 1988; Petty, Cacioppo, \& Schumann, 1983), or global, moral, and philosophical issues (e.g., Ostrom \& Brock, 1968; Sereno, 1968), neglecting to use intensely relevant issues that ask individuals to make choices that immediately and intimately impact their lives. Cigarette smoking is such an issue, and could provide more heuristic and, perhaps, more important insights into the ways people adopt or change attitudes and behaviors. Given the risk it holds for women, it is likely that cigarette smoking would be an especially personal issue for female smokers, and a useful one for an investigation into the effects of perceived relevance in the processing of, and responses to, persuasive communication. 
Finally, the creation and production of persuasive messages has been typically executed by the researchers. As a result, the messages most likely are mediated by the researchers' biases in terms of the focus, reasoning, language, and structure. Even when pretested, such messages may be extremely limited in the extent of relevance perceived by an intended audience. The most relevant messages would seem to be ones created by the audience itself. Audience members are the ones who are best able to express what is important and reasonable for themselves and to others like themselves, with language and in a style that speaks from similarity of lifestyle and experience. It would seem, therefore, that the participants whose behavior we are seeking to change need to be involved in the message making. It is common to hear smokers say they wish they had never started. They must not only guide the researchers in the making of the messages meant to dissuade others from following the same path; they must be allowed and encouraged to make the messages themselves.

In summary, cigarette smoking continues to be a serious health risk, especially for women. Efforts to intervene have not been effective with this high-risk group, and one reason suggested by the research is that intervention programs are neglecting particular psychosocial and motivational differences that may influence perceived message relevance. Persuasion research has been limited by investigating perceived message relevance as an assumed result of perceived issue relevance, ignoring the influence of message content on perceptions of relevance and the effect 
those perceptions might have on the process and outcome of persuasion. In addition, persuasion research has generally neglected to use potentially highly relevant issues, such as cigarette smoking, that profoundly link an individual's attitudinal and behavioral choices to the personal consequences of those choices. And, finally, messages purported to have differing degrees of relevance have been created by researchers, when the most relevant messages are more likely to be created by those who speak the same language and have the same life perspective as the intended audience.

This study intends to address these concerns and oversights through the creation and testing of "don't smoke" messages developed by and for adolescent females. Two messages will be created, their purpose being to dissuade junior high school females who are either experimenting with or inclined to start cigarette smoking. One message will be created by high school females who currently are cigarette smokers, and the other will be created by high school females who have never been cigarette smokers. These messages will be presented to junior high school students for their responses regarding perceived relevance and perceived effectiveness. Since the problem of resistance to intervention programs has been detected primarily in the female population, and since perceived relevance has been identified by elaboration likelihood model researchers as an important mediating variable in persuasion, one goal of this study is to test if messages created by females wouid elicit different perceptions of relevance from females than from males. Furthermore, 
considering the importance of relevance in persuasion, this study also hopes to test if smokers perceive more relevance in a message created by smokers than in a message created by non-smokers.

In addition, this study will explore the relationship between perceived relevance and perceived effectiveness when relevance is perceived from the content of the message, rather than assumed from group membership or pre-message instructions. To this end, subjects will be presented with the two messages without researcher-prefaced characterizations about the importance of the messages in order to investigate to what extent the subjects may determine relevance from the content of the messages, and how these perceptions of message relevance might influence their perceptions of effectiveness, regardless of assumed perceptions of involvement based on group membership.

The remainder of this chapter will review literature in two areas. The first literature review deals with cigarette smoking and intervention efforts directed toward female adolescents. The second review of the literature explores the influence of personal relevance in persuasion research. At the end of this chapter, the research questions that guide this project will be presented.

\section{Literature Review I}

Smoking Statistics. Intervention Programs, and Women-at-risk

\section{Smoking_Statistics}

Despite the immense and growing body of evidence linking increased health risks with tobacco use, an estimated 28.8 percent of the 
adults in the United States still smoke cigarettes (U.S. Public Health Service [U.S. DHHS], 1989). Smoking continues to be the single most preventable cause of death in the United States, where one out of every six deaths is linked to cigarette smoking (U.S. DHHS, 1989). Every year, 1.5 million people quit smoking (U.S. DHHS, 1989), but are replaced quickly as, each day, 3000 adolescents pick up and smoke their first cigarette (Glynn, 1989). The majority of cigarette smokers first experience cigarette smoking during early adolescence; $25 \%$ of all high school seniors who have ever smoked report having smoked their first cigarette before the 6th grade, and $50 \%$ report having smoked their first cigarette before the 8th grade (U.S. DHHS, 1989).

In "Reducing the Health Consequences of Smoking: 25 Years of Progress," (U.S. DHHS,1989), the Surgeon General succinctly states the pre-addictive scenario:

As long as children and adolescents continue to find reasons to use tobacco, replacements will be recruited for at least some of the smokers who quit or die prematurely. If current trends continue, these replacements will be found disproportionately among minority groups, among the less educated, among the most economically disadvantaged, and among women. (U.S. DHHS, 1989, p. i)

The Surgeon General's statement implies the urgency for intervention before adolescents, especially high-risk groups (e.g., women), become habitual cigarette smokers. 


\section{Intervention Programs: Success and Failure}

In an attempt to nip the problem in the bud (or butt, if you will) smoking intervention programs have been developed to target young adolescents before they become habituated to smoking. Programs developed in the early '70s adopted a cognitive, instructional style, trying to discourage cigarette smoking primarily by presenting adolescents with information about the health risks. In the late '70s and early ' 80 s, social influence programs based on social learning theory expanded these instructional programs, teaching students not only about the health hazards, but also teaching methods to help students develop self-esteem, and teaching social skills for resisting pressure from both advertisers and peers. In a review of existing school-based smoking intervention programs, Glynn (1989) reports that the programs "have had consistently positive effects, though these effects have been modest and limited in scope. They have been particularly effective in delaying the onset of tobacco use and less successful in targeting high-risk and minority youth" (p. 183). Generally, the programs have been successful at preventing or delaying the uptake of cigarette smoking by adolescents who indicate little or no inclination to smoke, but have not achieved similar results either with adolescents who have indicated a strong inclination to start smoking, nor with those who have become regular smokers. Although keeping the less-inclined on the right path is admirable, and should continue, smoking intervention programs need to discover further why high-risk individuals continue to resist intervention efforts, and to explore ideas that might lead 
to ways to reach this audience.

The limited reach of intervention efforts may be illustrated by one examination of a representative program. Burke, Salazar, Daugherty, \& Becker (1989) evaluated an application of Fishbein and Ajzen's theory of reasoned action (Ajzen \& Fishbein, 1977; Fishbein \& Ajzen, 1975) in an intervention program aimed at seventh-graders. This theory, say Burke, et al., "suggests that preventing the initiation of a voluntary behavior, such as smoking, depends on altering smoking-relevant beliefs and/or subjective norms" (p. 3). These researchers looked at this program's attempt to alter smoking-relevant beliefs through health-risk education, and its effort to influence subjective norms with knowledge and behavior competitions between groups. The results were positive for nonsmokers and occasional smokers (less than one cigarette per week), but negative for weekly smokers (more than one cigarette per week). The failure to influence the beliefs and norms of the weekly smokers suggests that weekly smokers either ignored or rejected the health-risk information. Additionally, the resistance to the normative manipulation suggests that weekly smokers do not wish to adopt the norms of non- or occasional smokers. The weekly smokers may be rejecting the pressures brought on them in this experiment because of their perception that the informational messages and normative standards are, for them, irrelevant. This may also be the case in other intervention programs that fail to influence those already inclined to smoke.

Some researchers have indicated that there exist important 
differences among smokers that may cause differences in the way the individual smoker responds to intervention efforts. Glynn, Leventhal, and Hirschman (1985) posit that adolescents are drawn to cigarette smoking by their beliefs that smoking will help satisfy one or more of three developmental needs: the need for social approval, the need for affect regulation, and the need for self-definition. The extent of any or all of these needs, and the extent to which adolescents perceive the instrumentality of cigarettes for satisfying these needs, serve as the basis for adolescents' motivations to smoke cigarettes. Intervention programs focused on peer pressure as the primary factor in adolescent smoking may be perceived as irrelevant by some smokers with other motivations to smoke.

The question of relevance is an important one, and will be discussed in more detail in a later section. The concept is raised here to make the point that relevance may vary greatly by the particular interests, needs, and concerns of a particular audience. A failure to influence a particular audience may be the result of ignoring these interests, needs, and concerns, resulting in that audiences' perception that the communication is, for them, irrelevant. One audience that has been most difficult to influence is that comprised of female adolescent smokers.

\section{Women-at-risk For Smoking}

While the overall number of smokers has been decreasing, this is less true for women than for men. The Surgeon General concluded that the decline in cigarette consumption in this country is due to higher rates of smoking cessation among men and lower rates of smoking initiation 
among male adolescents (U.S PHS, 1980). In 1977, as many female adolescents were smoking a half a pack of cigarettes a day as were males, and in 1990, female high school seniors outpaced their male classmates smoking one or more cigarettes per day, with a rate of $19.3 \%$ vs. $18.6 \%$ ("Tobacco use," 1990).

Cigarette smoking has been linked with increased health risks particular to women, including premature or low-birthweight babies (U.S. DHHS,1989), cervical cancer (Fackelmann, 1991), tubal pregnancy ("Smoking boosts risks," 1991), and heart failure for those using oral contraceptives (U.S. DHHS,1989). Considering the multiple health risks associated with both cigarette smoking and female reproductive concerns, it is alarming that a survey from the Centers for Disease Control found that one out of every three reproductive-age women is a cigarette smoker ("Federal survey," 1991). In addition, lung cancer has overtaken breast cancer as a more prevalent threat to womens' lives (Baker \& Sherman, 1991; Harris, 1984; Stolley, 1983), increasing lung cancer related deaths for women by $300 \%$ in the last twenty years (Amos \& Chollat-Tarquet, 1990). The Surgeon General, noting the threat cigarette smoking presents to women, advised early intervention:

The key to addressing this problem is the prevention of smoking among female adolescents. The disparity in smoking prevalence between men and women is primarily a reflection of differences in smoking initiation. Smoking initiation has declined much more slowly among females than among males. (U.S. DHHS, 1989, p. vi) 
In spite of the particular need to address this population, intervention efforts have not demonstrated great success with female adolescent smokers. Some researchers suggest that one reason for this failure is that female adolescent smokers are not the "typical teenage smokers" intervention program developers have in mind when developing their programs.

Gilchrist, Schinke, and Nurius (1989) reported evidence that young women are more resistant than men to smoking intervention programs, and believe this resistance can be attributed to developmental and social differences. Demographic and psychosocial characteristics were compared among 6th-grade girls and boys who were either at high or low risk for future habitual smoking. High risk individuals were described as those who had experimented with cigarette smoking, or hacl intentions to do so in the near future. High-risk girls demonstrated significantly greater resistance to intervention efforts when compared to high-risk boys, low-risk girls, and low-risk boys. While the differences in intervention effectiveness between high-risk and low-risk students might be anticipated, and is supported by other research, the differences between high-risk girls and high-risk boys raises questions about the causes for these differences. Certain psychosocial differences and similarities discovered among the four groups provide some clues.

Measuring the subjects' self-perceptions about their social behavior skills (responding to peer pressure) and self-efficacy (success and attractiveness relative to peers), Gilchrist, Schinke, and Nurius found that 
the high-risk girls possessed significantly greater behavioral skills and perceived self-efficacy than the high-risk boys. Additionally, the high-risk girls indicated significantly greater willingness to engage in risky behavior (e.g., drinking beer, skipping school) when compared to the low-risk girls, but were statistically similar in this measure when compared to both the high- and low-risk boys. Referring to the various motivations to smoke discussed by Glynn, Leventhal, and Hirschman (1985), Gilchrist, Schinke, and Nurius assert that the psychosocial differences indicate important distinctions in female adolescent needs, abilities, and strategic choices that result in important distinctions in female adolescent motivations to smoke.

For example, although male adolescents may use cigarettes to enhance their relationship with a certain group, female adolescents demonstrate greater self-confidence in social settings and are less likely to use cigarettes for social approval. In addition, male adolescents may have options to express independence and assertiveness that are not culturally available to females, thus increasing the likelihood that females will utilize cigarette smoking for this purpose. And, finally, Gilchrist, Schinke, and Nurius report a great deal of research indicating that females are more likely than males to smoke cigarettes to regulate emotions. They cite studies that indicate women tend to be more highly self-monitoring and more analytical of their inner feelings than men. Females have been found to be more likely to find ways to cope with tension and worry rather than resolving the external conditions that cause the worry and tension. 
Cigarette smoking, for these individuals, can be such a coping technique.

Gilchrist, Schinke, and Nurius believe that the psychosocial differences between high-risk girls and high-risk boys, and between high-risk and low-risk girls are likely responsible for the greater resistance to intervention found for female adolescent smokers. They argue that current intervention programs, designed to teach social skills (e.g., learning how to say no), ignore distinctive psychosocial differences found in female adolescent smokers. As a result, these programs address concerns that are less relevant for female adolescent smokers than for males. Efforts must be made to investigate ways to present more relevant information, with more relevant communication, that are responsive to the particular needs, concerns, and motivations of female smokers.

\section{Literature Review II}

\section{Relevance. Involyement, and Persuasion}

In the research exploring involvement in the process of persuasion, two theoretical approaches have emerged: one from social judgment-involvement theorists (e.g., M. Sherif \& Hovland, 1961), and the other from cognitive response researchers, (e.g., Petty \& Cacioppo, 1979, 1984). The term involvement has been used to refer to the extent to which individuals perceive a relationship between an issue or object and themselves. However, the operationalization of involvement and related constructs has varied somewhat by the kind and character of that relationship. In addition to differences in operational definition, involvement has appeared to produce seemingly conflicting effects on 
attitudes and behavior, with social-judgment theorists arguing that highly involved subjects resist persuasion, and cognitive response theorists arguing that involvement may, sometimes, enhance persuasion. Responding to these concerns, recent discussions in the literature have debated ways to distinguish one type of involvement from another. Types of Relevance

In a meta-analysis of the persuasion studies that explore the influence of involvement, Johnson and Eagly (1989) have argued for distinguishing three different types of involvement, which they classify as "value-relevant involvement," "outcome-relevant involvement," and "impression-relevant involvement." Johnson and Eagly base these distinctions on the different kinds of receiver-concerns that are manipulated by researchers in their study of involvement. For example, Johnson and Eagly believe that varying the way an issue interfaces with a receiver's value system is different from varying the way and extent the issue is perceived to impact, potentially, the receiver's daily life. The former, they argue, would elicit "value-relevant involvement," whereas the latter would elicit "outcome-relevant involvement." The third distinction, "impression-relevant involvement," refers to a state evoked by a subject's belief that she or he will be asked to state publicly and/or argue an opinion after being presented with a persuasive message.

Johnson and Eagly believe that the distinctions of these different types of involvement are in part attributable to the different theoretical perspectives guiding the research. They state that "impression-relevant 
involvement" has been explored through cognitive dissonance and self-presentation studies (e.g., Chaiken, 1980; Leippe \& Elkin, 1987; Zimbardo, 1960), "value-relevant involvement" has been explored in the research of social judgment-involvement researchers (e.g., Ostrom \& Brock, 1968; C. W. Sherif, Kelly, Rodgers, Sarup, \& Tittler, 1973), and "outcome-relevant involvement" has been examined by cognitive response theorists (e.g., Petty \& Cacioppo, 1979, 1981, 1984). While there seems to be no disagreement that "impression-relevant involvement" is specific and distinct from the other two types identified by Johnson and Eagly, cognitive response theorists Petty and Cacioppo (1990) argue that the distinction between value-relevant and outcome-relevant types of involvement lacks merit or foundation.

In the social-judgment research, high involvement is associated with resistance to persuasion. In contrast, in cognitive response research high involvement has often been shown to increase persuasion. Johnson and Eagly argue that the way involvement is operationalized in each of the two different research traditions accounts for the different results, in that social-judgment researchers use value-relevant issues, while cognitive response researchers use outcome-relevant issues. Petty and Cacioppo (1990) have responded that the differences found in the effects of involvement are not due to different types of involvement, but, rather, due to an interaction effect of involvement with other variables. In their "elaboration likelihood model" (i.e., Petty \& Cacioppo, 1979), the researchers posit that involvement alone does not determine acceptance or rejection of 
a persuasive message; rather, it influences the state of motivation, determining how and to what extent a receiver exerts cognitive effort to process a persuasive message. When personal relevance is high, the individual is motivated to expend cognitive effort to evaluate the various components of the persuasive event, including source credibility, argument quality, and other variables. The essential concern, they say, is whether the individual feels that the issue is personally relevant to that individual, regardless of whether the relationship is with the individual's value system, or with concerns about impending actions that may impact on her or his life. They argue that results from social-judgment research showing less persuasion under conditions of high involvement can be explained by the likelihood that subjects had already formed strong biases on the issues. Petty and Cacioppo state that strongly rooted predispositions act as an interacting variable with involvement, providing subjects with material for counterarguing any potentially favorable thoughts triggered by the persuasive message, thus inhibiting persuasion.

The research sonducted by Petty and Cacioppo supports their position that involvement is a mediating variable interacting with other variables to produce effects, and they believe their position is supported in social-judgment research as well when other variables are taken into consideration. The predictions of the elaboration likelihood model could be tested more thoroughly by using issues that may be aptly called value-relevant, or by using issues that are both value-relevant and outcome-relevant. To extend the investigation of the influence of 
involvement, we need to look at what issues have been applied so far, and consider how other types of issues may enhance our investigation. Issues Used in Relevance Research

Social-judgment research generally uses global issues to operationalize the involvement construct, seeking responses to moral, social, political, and philosophical matters, (e.g., birth control, the morality of the Vietnam war, government economic policy). The issues raised in cognitive response research, on the other hand, have been more specific, either asking subjects to respond to arguments for or against institutional policies that may affect their present college life (e.g., tuition raises, compulsory exams, coed dorms), or asking subjects to indicate their behavioral intention to buy or not buy a product (e.g., shampoo, disposable razors). Both research perspectives have used issues that may be perceived as important or relevant by the audience (typically, college students), but have focused either on actions to be carried out by the society or institution, or on a one-time behavioral decision, asking subjects to indicate their intention to purchase a product. What is missing from these studies is an exploration of issues that address the subjects' own current and ongoing attitudes and behaviors that more profoundly and more directly impact their own physical and/or psychological health, as well as that of significant others.

It would be more useful and meaningful for researchers to investigate the effects of involvement by asking subjects to change attitudes about their own behaviors, or to change the behaviors themselves, when it 
is within their personal capacity to do so, rather than asking them to change their attitudes about global or institutional issues, or simply to make purchasing choices. Issues of greater personal consequence, requiring more personal and tangible responses from subjects, might be defined as "intimate" issues; these issues should result in more intense perceptions of personal relevance, perhaps better referred to as "intimate relevance." This application of intimate issues in persuasion research would enhance the potency of the involvement construct by focusing on matters that depend directly on the attitudinal and behavioral responses of the message recipient.

An area of research that does address intimate issues is that of health communication, but the study of involvement as a variable is not usually done. This is probably because it is assumed that, by virtue of their membership in the intended audience, the subjects are necessarily "involved." But involvement with the issue is one variable, and involvement with the message might be considered another. Although subjects may be intimately involved with the issue, how a subject perceives the relevance of the persuasive message is likely to have equal, if not more, impact on how the subject responds to the message. Assuming that subjects will care about and feel involved with the message because of their involvement with the issue overlooks the perceived relevance of the message itself as it impacts attitude formation and behavioral intentions. 
Qperationalization and Manipulation of Relevance: Group Membership and Pre-message Relevance ys. Message-content Relevance

In studies exploring involvement and persuasion, efforts to create varying levels of involvement have been attempted, primarily, by manipulating perceptions of issue relevance. One method manipulates the importance of the issue by presenting groups with two different issues chosen by the researchers; one that is presumably more relevant, and one that is presumably less relevant for the subjects (e.g., appropriate maleand female-related career choices vs. a new comedian's odds for success on television, C. W. Sherif, Kelly, Rodgers, Sarup, \& Tittler, 1973). Another method presents the same issue in the same way to two different groups who, as determined by group membership and/or by pretest, attribute either great or little importance to the issue (e.g., desirability of unmarried women using contraceptive pills, Sereno, 1968). A third method, used extensively by the cognitive response researchers, creates two different prefaces for the same message; one introduction to the message states that the issue being discussed will affect the subjects quite soon, and the other states that the issue is being considered by another population entirely, not affecting the subjects in any way (e.g., requiring comprehensive exams for seniors, Leippe \& Elkin, 1987; co-ed dorms, Petty \& Cacioppo, 1979). Each of these methods, though useful to a point, has shortcomings. The first, presenting two different issues, cannot measure how different levels of involvement affect the responses of subjects in a single population to persuasive messages about one issue. The second, using two different 
groups, presupposes consistently polar and predictable responses from the members of each group regarding the issue under consideration. The third method, prefacing the same message with two different qualifiers, presumes that perceived message relevance is increased by manipulating the perceived issue relevance, and asks subjects to judge, a priori, that the message is one that should or should not concern them.

All of these methods used to manipulate involvement attempt to define or influence the receiver's relationship with the issue before the message has been transmitted, and each makes assumptions about the motivational state that results from that relationship. These methods do not consider the receiver's response to the message itself; that is, whether the subjects perceive the message as personally relevant based on the content of the message.

It would seem worthwhile to elicit responses to the message itself, including subjects' evaluation of its relevance, for this may provide more insight to how individuals use the content and context of the message to help determine how and what to do with it. With that purpose, this study will proceed with the position that message relevance refers to the perceived relevance subjects indicate as a response to the content of the message itself; it does not refer to subjects' perceived relevance of the issue, nor to any possible transfer of perceived relevance from issue to message, nor to relevance perceived due to directives given by the researcher. 


\section{Operational definition}

Message Relevance: Message Content and Message Development

\section{Message Content}

Beyond the overt purpose of a persuasive message, there are features of the message content that may influence perceptions about message relevance. Among these are the particular pros and cons surrounding an issue that are raised in the message, addressing areas of concern that may or may not be perceived as relevant by some individuals. Additionally, the words, syntax, language style, and perspectives taken may provide clues about the character of the message source; and that source, as well as the source's experience and opinion, may not be considered relevant by some individuals. Cigarette smokers, for example, are likely to feel involved with the issue in a message intended to discourage smoking, yet believe that the concerns raised, points covered, or conclusions drawn in the message are, for them, personally irrelevant. Likewise, the language and syntax of a message may suggest a source with whom the smoker feels no rapport, or with whose perspective on the issue the smoker feels at odds. These two aspects of message content, argument quality and implications about the source based on language and perspective, seem likely to influence perceptions of message relevance, and need to be considered when investigating the relevance of persuasive messages.

Relevance and Argument Quality

Elaboration likelihood model researchers have explored the impact of the elements of messages by manipulating the quality of the arguments 
used in a message (e.g., Petty \& Cacioppo, 1984). However, operationalization of these variables has been limited somewhat by the researchers' assumptions about what makes an argument "strong" or "weak." Petty and Cacioppo state that, if recipients are motivated to process the content of a persuasive message, the "arguments" are what recipients evaluate to determine the merits of the position recommended. A complication arises, however, because individuals have differing beliefs about what information is central to the issue under consideration. Petty and Cacioppo state that "the kind of information that is relevant to evaluating the central merits of a product or issue may vary from situation to situation and from person to person" (1986, p. 17).

An example of how different people attribute importance to different information is found in the advertising study by Snyder and DeBono (1985) where subjects were asked to respond to ads containing either information about the quality of a coffee product ("A delicious blend of three great flavors"), or to those with implied affective product associations ("a cozy evening"). Those subjects that were measured as "high self-monitors" were more likely to choose the coffee if presented with the "affective" ad, while "low self-monitors" expressed more interest when presented with statements about the quality of the product. If asked, it is likely that each group would report that they responded to what they believed was information that was important and central to an evaluation of the product. Petty and Cacioppo argue that "arguments" refers to any information contained in a message that permits a person to evaluate the 
message target (e.g., issue, object, person) along whatever target dimensions are central for that person" (Petty \& Cacioppo, 1986, p. 18). They further state that either affective or cognitive considerations can be considered, by a recipient, to be of importance when evaluating the merits of the position in the persuasive message. However, having said that, these researchers and others in the cognitive response perspective tend to develop and use arguments that range from "strong" to "weak" on a rational or cognitive continuum.

In developing strong and weak arguments, Petty and Cacioppo use an elaborate process starting from the generation of a large number of arguments favoring a position that they intuitively believe to vary in strength. These arguments are rated for strength by members of the subject population, resulting in one strong and one weak argument. These arguments are then given to other members of the subject population who are instructed to list thoughts that are elicited by the arguments; those that produce predominantly favorable thoughts are considered to be "strong" arguments, while those that produce predominantly unfavorable thoughts are considered to be "weak" arguments (Petty and Cacioppo, 1986). One difficulty with this process is that, while the strong arguments may be perceived that way by most of the population, a segment of the population that may be important to reach may be more influenced by so-called weak arguments. An example from Petty and Cacioppo will help to illustrate this point.

Petty and Cacioppo (1986) present examples of strong and weak 
arguments for raising tuition at a university. A strong argument for raising tuition, they say, would be that the university can buy more books for the library, while a weak argument for raising tuition would be that the university can plant more shrubs and trees on the campus. However, granting that the overall population may accept the book buying rationale as a stronger argument than the tree planting rationale, some students (e.g., environmentally conscious students), may perceive the tree planting rationale as the stronger argument. This is not to suggest that the process used by Petty and Cacioppo does not work; it only argues how important it is to consider the specific interests and concerns of a particular intended audience when evaluating which arguments are strong and which are weak. As stated by Petty and Cacioppo (1986), "people will invariably differ in the kinds of information they feel are central to the merits of any position" (p. 16).

Another weakness with this method for developing different persuasive messages is that it limits the creation of strong and weak arguments to the extremes that have been defined by the researchers. It is possible that the rationale for attitudes and behaviors of some sub-set of the population may be considered weak, and even irrational to the researchers, and even to most people. But a tendency to consider only "rational" arguments is likely to limit the possibilities when majority opinion determines what arguments are strong arguments.

In addition, while researchers pretest their messages to measure relative argument strength, subjects may perceive argument quality in 
other features conveyed in a message. One such feature that is likely to influence perceptions of credible argumentation is the perception of a credible source.

\section{Relevance and Source Credibility}

Credibility is often associated with expertise, but credibility can also be attributed equally to message sources who have much in common with a message recipient. Evidence suggests that perceived source similarity will encourage persuasion (McGuire, 1969). If the similarity perceived is based on common experience, and this common experience is relevant to the issue, subjects will attribute greater credibility to the source, increasing persuasion (Berscheid, 1966). In fact, subjects may attribute more credibility to similar sources than to expert sources (Brock, 1965). Brock found that customers were persuaded more about which brand of paint to use when dealing with sales people having similar kinds of paint experience than with sales people who had much more painting experience.

Perhaps one reason we rely on non-expert but similar sources is that attitudes depend not only on our beliefs, but also on our values regarding an issue. Haas (1981) points out that experts may influence our beliefs about an issue, but peers influence our evaluations of the beliefs. When an attitude about an issue is highly dependent on the values we associate with an issue, we are more likely to attribute credibility to a source that shares our interests, perspectives, goals, and behaviors, than to a source who is scholarly about the issue (Haas, 1981). 
Although the impact of source credibility on persuasion has been studied, the variable is usually manipulated by providing the subjects with information about the source's background that purports to indicate a certain level of expertise on an issue. No work has explored how recipients respond to similarities between the source and recipient that might be inferred from the message itself. It would seem likely that, without revealing specific information about the message source, features of the message such as the particular concerns raised, arguments made, and language used might serve as cues about the commonality of experience between the recipients and the source. If this were to occur, perceived similarities may influence perceptions of credibility, increasing perceptions of message relevance.

Developing Relevant Messages: Media Campaigns/Intervention Programs

The whole message, meaning the unstated as well as stated message, has been of particular interest to researchers in the areas of advertising and public health media campaigns. Intervention programs could learn from this area of research because, like advertising and media campaigns, these programs are planned and structured communication events intended for a mass audience. Atkin and Friemuth (1989), in an article on advertising and public health campaigns, discuss one method used to enhance relevance in the language and style of persuasive messages.

Producers of advertising campaigns have used focus-groups, groups of individuals who have interest in, knowledge of, and/or experience with a 
type of product, to help them produce more relevant and effective messages. Typically, a small group will meet with a moderator who encourages a dialogue among participants for the purpose of eliciting their ideas and concerns about a product or issue. From this discussion, the producers identify consumers' concerns, as well as particular language and style characteristics, to help them in the creation of media messages.

Atkin and Friemuth state that this method has been used primarily by product advertisers, but has not been utilized enough by producers of public health campaigns. Instead, producers of health campaigns have typically developed their messages without input from intended audience representatives. Inviting members of the affected population to discuss their beliefs and concerns surrounding a health issue would be of immense value in the creation of messages intended to help influence that same population.

In the case of cigarette smoking, adolescent female smokers could provide, in a focus group setting, ideas that would be most relevant to other members of this high risk group, and do so in language that would increase perceptions of relevance of the message. But even these ideas and language might be altered if filtered through a researcher on the way to becoming a finished message. Therefore, as an extension of the focus group concept, the representatives of the intended audience who form the focus group should not only contribute to a discussion about the planned message, but become involved in the actual creation of the persuasive message itself. In this way, it is more likely that the ideas, concerns, 
language, and style of the message will be perceived as truly relevant, in many respects, by the intended audience: the female adolescent smoker.

Summary and Research Questions

Efforts to intervene with the experimentation and initiation of women smoking cigarettes have not been very successful. Research has shown the important role played by perceptions of relevance when receivers are deciding if and how to process a persuasive message. The ineffectiveness of intervention programs for female smokers may be due to motivational and psychosocial differences; differences that have not been considered or addressed in these programs, the result being that the program messages are perceived as irrelevant by both female smokers and female adolescents who are inclined to become smokers. Therefore, research needs to explore ways to make these "don't smoke" messages more relevant for female smokers.

As discussed in this chapter, message relevance could be increased by recognizing and addressing in the message the particular motivations, needs, interests, and concerns of the particular audience one is trying to reach. Furthermore, the relevance of the message depends not only on the relevance of the issue, but on the perceived relevance of the message itself, including elements of the message such as the ideas raised, the arguments made, the reasoning used, the words chosen, and the style presented, as well as message cues that may imply information about the source. Persuasive messages made by researchers run the risk of being perceived as irrelevant due to biases that may mediate any of the above 
listed elements. The most relevant messages that address the particular concerns of a group, raising issues that are important to that group, in language and style familiar to that group, and generally represent the perspective of members of that group are likely to be made by members of that group. Therefore, relevance is likely to be increased by enlisting members of the intended audience itself in the actual creation of persuasive messages.

As well as trying to explore particular ways to improve smoking intervention programs, this study hopes to extend the research on relevance and persuasion in three ways: (1) by utilizing intimate issues in the research; intimate issues being those that ask subjects to make attitudinal and behavioral choices that have immediate, proximal, and consequential impact on their own lives, (2) by investigating perceived relevance that results from the content of a message, as opposed to relevance assumed from group membership, pre-test measures, or qualifiers produced by experimenters, and (3) by exploring the potential for increasing message relevance by using persuasive messages actually created by peer member focus groups.

To these ends, a group of female adolescent smokers will create a "don't smoke" persuasive message for slightly younger females who have either just begun or indicated an inclination to engage in cigarette smoking. In order to compare the communication of those who are experienced with those who are not, a group of female adolescents who have never smoked regularly will also create a "don't smoke" message for 
the same audience.

Both messages will be presented to junior high school students, both females and males, to measure their responses in terms of perceived relevance and perceived effectiveness. The audience members will also be measured in terms of their experience with cigarette smoking, as well as their current status as smoker or nonsmoker.

This study has taken the position that those with direct experience with a particular behavior are more likely to create more relevant messages for those who are inclined to become involved with that behavior. In addition, according to the elaboration likelihood model, increased perceived relevance is likely to enhance persuasion. Therefore, the following research questions are to be explored:

RQ 1: a. Will female cigarette smokers perceive the Smokers Group PSA as more relevant than the Nonsmokers Group PSA? b. Will female cigarette smokers perceive the Smokers Group PSA as more effective than the Nonsmokers Group PSA?

RQ 2: a. Will females who have tried cigarette smoking perceive the Smokers Group PSA as more relevant than the Nonsmokers Group PSA?

b. Will females who have tried cigarette smoking perceive the Smokers Group PSA as more effective than the Nonsmokers Group PSA? 
RQ 3: a. Will group membership in terms of gender, smoking experience, and smoking status be associated with differences in the psychosocial variable risk-taking orientation?

b. Will group membership in terms of gender, smoking experience, and smoking status be associated with differences in the psychosocial variable perception of self-efficacy?

RQ 4: a. Will group membership in terms of gender, smoking experience, and smoking status be associated with differences in perceived relevance of either or both of the PSAs?

b. Will group membership in terms of gender, smoking experience, and smoking status be associated with differences in perceived effectiveness of either or both of the PSAs?

RQ 5: Will perceived message relevance, risk-taking orientation, and perception of self-efficacy influence perceptions of effectiveness?

The research design and methods used to explore these research questions are presented in the following chapter. 


\section{CHAPTER II}

\section{Methods}

Given the literature reviewed and research questions raised in Chapter I, this project proceeded in two phases: (1) the creation of two "don't smoke" messages that, created by groups with differing intimate experience with the issue, might be responded to with differing degrees of perceived relevance, and (2) a survey to measure the intended audiences' responses to those messages in terms of perceived relevance and effectiveness. Chapter I argued for the probability that messages would more likely be perceived as more relevant by the intended audience (i.e., adolescent female smokers) if created by persons who share similar demographic and experiential characteristics (i.e., adolescent female smokers). It was also argued that the actual message content should be considered when measuring perceived relevance, rather than relying on experimenter-produced efforts to induce perceptions of message relevance. Furthermore, although focus-groups have been used to help message makers produce persuasive messages, their contributions are usually mediated by the professionals (e.g., researchers, television producers) in their efforts to conform the message to traditional expectations of professional message making. To measure the influence of perceived relevance for a message actually created by individuals similar in important experiential characteristics as the intended audience, such a message would have to be created, and perceived relevance of that message would have to be measured. 
The first phase of the project was to create a "don't smoke" message in the form of a public service announcement (PSA), produced by adolescent female smokers for other adolescent females who either have become smokers or have indicated an inclination to become smokers. To investigate the specific influence similar experience would have on perceived relevance, two PSAs would be produced; one by each of two groups that were similar in aspects except in their smoking experience. To this end, one PSA would be produced by high school female smokers, and another PSA would be produced by high school female nonsmokers. It was decided to use high school smokers to produce these PSAs because they are still close enough in age to those individuals who have begun to experiment with cigarette smoking (e.g., young adolescents), but old enough to have some personal knowledge about how cigarette smoking has affected their lives.

Phase 2 of this project involved measuring the perceived relevance and effectiveness of the PSAs by the intended audience: female adolescent smokers and experimenters. Since early adolescence has been identified as the time when individuals are most inclined to experiment with and initiate cigarette smoking, it was decided to present these two PSAs to junior high school female adolescents, and to measure their perceived relevance of the PSAs through a questionnaire. Although the focus of this study is to investigate the perceived relevance for the high-risk group, adolescent female smokers, it is also concerned with how perceived relevance of these PSAs might be different for different audiences not 
similar to the message source. Therefore, the PSAs would be presented to both adolescent females and males, smokers and nonsmokers.

\section{Phase 1: The Creation of the PSAs}

In a discussion on field experiments, Kerlinger (1973) articulated an area of difficulty that field researchers are likely to encounter. These difficulties arise due to the status of some subjects as participants in an active institutional environment. For example, if a researcher wishes to conduct research with students in the public school system, logistical and other concerns of administrators and teachers may make it difficult to persuade these school officials to involve themselves or their students in such a study. Praising the value of field experiments, Kerlinger encourages researchers to "be prepared to spend many hours, even days and weeks, of patient discussion with people responsible for the institutional or community situation in which he is to work" (p. 404). Kerlinger adds that the researcher needs to be "socially skilled," possessing a high degree of what is now often referred to as communication competence.

The consent and cooperation of teachers and administrators can often be obtained if a proper approach, with adequate and accurate orientation, is used, and if explanations of the reasons for the use of specific experimental methods are given. (p. 404)

The difficulties raised by Kerlinger were encountered in this study. Finding and employing subjects with the requisite characteristics (e.g., female adolescent smokers) required both persistence and concise, clear 
communication about the aim and design of the study, repeated many times to many people. The following description of the process is not meant to be a criticism of the institutional authorities; their responsibilities for and obligations to their charges appears to be, and should be their paramount concern. It is offered to illustrate that the issues addressed by Kerlinger have been confirmed in this study, and to present a realistic picture of the potential problems one may encounter when conducting field research.

Phase 1 required the formation of the two PSA production groups. Many problems were encountered in the effort to find participants. In all, it took about eleven months to find a school and students willing and able to participate. Most of this time was spent in the effort to contact, discuss with, and secure approval from school administrators and teachers.

The researcher attempted to contact county school department officials, local school district administrators, high school principals and vice principals, and individual teachers for their assistance. Often, the appropriate person to talk with was not available, but would, the researcher was assured, get back to him. This rarely happened and, after allowing an appropriate response time to pass, the researcher would persist by calling again and again. It is clear from this experience that all of these individuals are under great time and energy constraints due to the already pressing job of education in the public school system. There developed great concern on the part of the researcher that the necessary contacts in the schools would consider the researcher a pest and, therefore, 
choose not to assist in the project. This researcher became torn between a belief that the project would be a valuable one for the schools and students, and a belief that the project was an additional burden that school officials and teachers could not or would not be able to accommodate.

Once finally contacted, most school officials and teachers responded favorably to the project, but indicated that they would need to discuss it with others in the school system, and/or that they would have to explore how such a project could be conducted in a way not to disturb the current school program. This led to more difficulties like the ones described above; many more unreturned phone calls and much more uncertainty that the project could proceed.

Eventually, some school officials agreed to assist in the project, but logistical problems emerged. Although permission was granted to work with students, the demands of the school schedule made it difficult to put enough students together to meet at one time during the school day. This was especially true for female smokers as, both statistically and in these cases, there are many fewer smokers than nonsmokers, and only about half of these smokers are female. For example, at one school, two female smokers would be able to meet during one particular class period, but two other female smokers could not meet during that time. In that case, the teacher and vice principal were willing to allow the two smokers to meet during the time they were in her class, but were not receptive to asking other teachers to release the other smokers from their classes during that same time period. The lunch period was suggested as an option, but some 
of the students were committed to other school activities during that time. Recruiting the PSA Production Team

Finally, one administrator at a Northern California suburban public high school expressed interest in assisting the project. This administrator, whose title is Student Liaison Officer, works with students who have been disciplined for behaviors counter to school policy, including cigarette smoking, and, therefore, was able to recruit female smokers for the project. It was clear during a meeting attended by this administrator, the recruited students, and the researcher that there was a high degree of mutual respect between the administrator and these students, and that the students were being invited to participate without promise of reward or threat of sanction. The students were told that the researcher believed that they, as adolescent female smokers, had the potential to create very effective messages to discourage younger girls from starting to smoke and, if they would like to participate in this project, he would help them create "don't smoke" PSAs intended for junior high school girls. They indicated that they did not want to tell anyone else what to do, but that they would like to discourage others from becoming smokers as they had. The students volunteered to participate, and it was agreed that production meetings would take place during the lunch period on days that would be mutually agreeable.

At the same high school where the smokers were recruited, a communication teacher invited four non-smoking female students to participate. These students were told about the project in the same 
manner as the smokers, except that they were told that the researcher believed that they, as adolescent females, had the potential to create very effective "don't smoke" messages for junior high school girls. They were very enthusiastic about the project, and volunteered. The students agreed to meet with the researcher during the lunch period on selected days.

Meeting with the researcher in separate groups, the smokers (Smokers Group) and the nonsmokers (Nonsmokers Group) were reminded that their goal was to create "don't smoke" PSAs directed at junior high school girls, both to deter non-smokers from starting, and to encourage current smokers to quit (PSAs were defined for the students, and examples, such as "buckle up" and "don't drive drunk" PSAs, were discussed). All of the Smokers Group were seniors, and all were age 17. The Nonsmokers Group was composed of three sophomores, two age 16 and one age 15, and one junior, age 16.

Each group member was given a questionnaire to ascertain demographic information, the extent of their direct experience with cigarette smoking, and the amount of smoking engaged in by their parents, siblings, and friends (see Appendix A). The questionnaire also asked the students to respond on Likert-type five point scales to three statements regarding their beliefs about their own or other persons' motivations to initiate cigarette smoking. One statement pertained to "affect regulation" as a motivation, the second statement pertained to "social affiliation" as a motivation, and the third statement pertained to "self-identification as an adult" as a motivation. Three similar statements 
were then used to elicit the students' responses regarding their beliefs about their or others' motivations to continue to be regular cigarette smokers. Two open-ended questions asked the smokers to express, in their own words, why they thought they started smoking and why they thought they continued to smoke. Non-smokers responded "not applicable" to these questions. Both groups were then asked, in a final open-ended question, what messages they might create to discourage younger adolescent girls from cigarette smoking.

During preliminary discussions, all participants indicated to the researcher their willingness to help dissuade younger girls from smoking cigarettes. The Nonsmokers Group members expressed a clear dislike for the behavior and a strong interest in deterring others from smoking. The Smokers Group members expressed some frustration that they had become addicted to a behavior they believed was harmful, and interest in trying to prevent others from becoming similarly addicted.

\section{Focus Group Meetings}

The researcher facilitated five focus group discussion sessions with each group, separately, during a period of three weeks. The members of each group were aware that the researcher was also meeting with the other group, and were also aware of the differences between the groups, but no member in either group knew the identity of the members in the other group. The researcher was concerned that there would be cross contamination of ideas between the two groups, but, because the high school population is so large, and because the social environments of 
members of each group were quite different, this did not become a problem. For example, the Nonsmokers Group members stated that the people they associate with do not smoke cigarettes, and the Smokers Group members said that they spend most of their social time only with themselves and their boyfriends. In fact, members of each group were mildly curious about who members of the other group were. The researcher explained that, for the integrity of the project, he preferred not to reveal the names of other group members. Members of each group agreed that not knowing was better for the project, and did not pursue the subject further.

Each focus group discussion lasted approximately forty-five minutes, and was held at the school during the lunch period in the regular school day. The students were asked to consider why they thought some junior high girls started smoking, why some continued to smoke, and what message content and style they thought might be effective in deterring or intervening with smoking by junior high girls. During these sessions, the researcher clearly indicated that he was interested in their beliefs, opinions, and ideas, and that they should not be concerned with his approval or disapproval. They were told that he believed them to be the experts on life as adolescent girls, and that he was there to help keep them on task, and to bring his experience in video production to help them realize their ideas on videotape in the form of PSAs. The researcher encouraged all of their ideas, and often returned their questions about what he thought with the reminder that he really believed it was more important what they thought. 
During the discussion sessions, members of each group expressed thoughts about why some junior high girls started smoking, as well as a number of different ideas about what message content and structure they wanted for their PSAs. The first session, for each group, was filled primarily with the individual members discussing their own exposure to, experience with, and reaction to cigarette smoking, often followed by the members' ideas about why some junior high girls start smoking. During the second session, members started brainstorming ideas about how to create messages that would discourage junior high girls from initiating cigarette smoking. Many suggestions came out of this meeting, and the groups were advised to refine some of the ideas for the next meeting. By the third meeting, each group had developed two strong scenarios for the PSAs and debated the merits of each. Not wishing to influence their final decision, the researcher told the participants to give more thought to the proposed ideas and come to the fourth meeting planning to reach a consensus about one. At the fourth meeting, the Nonsmokers Group reached a consensus about the scenario they preferred, and completed a detailed script at the fifth meeting. The Smokers Group had more difficulty deciding on one scenario, so it was decided during the fourth meeting that both ideas would be scripted and videotaped, and that they would then choose the one they preferred after viewing the videotapes. The scripts were completed at the fifth meeting, and plans to videotape the PSAs were finalized. 


\section{Producing and Editing the PSAs}

The researcher videotaped the scenes under the supervision of the members of each group. The first Smokers Group PSA involved a number of scenes depicting the problems smokers encountered as cigarette smokers, including scenes of not having enough money to do other things because of the expense of cigarettes, being out of breath during physical education class, and arguing with a parent about the smoker's habit. The second Smokers Group PSA simply showed a discussion by the smokers sitting around a picnic table, focussing on the things they didn't like about being cigarette smokers, including confrontations with parents, attributions made by other students that they are drug users, and despondent feelings about having developed an addiction to cigarettes.

The Nonsmokers Group PSA presented images of a car exhaust pipe billowing smoke, intercut with scenes of a girl smoking a cigarette. After a couple of switches back and forth between the two scenes, the smoker made a short plea to the camera for the citizens to do something about air pollution. This plea was followed by words on the screen that said, "Why pollute the earth?" These words disappeared and were followed by words that said, "Why pollute your health?" These words then disappeared and were followed by the words, "Why smoke?" These video graphics were produced in a television studio and added to the PSA per instruction of the Nonsmokers Group members.

After completing the videotaping for both groups' PSAs, the researcher edited the shots with instructions supplied by the group 
members. Each group was then shown the edited results. The Smokers Group decided that they preferred the PSA showing them having a discussion around the picnic table, but felt that some lighting problems and some of the wording they used made the finished product less than satisfactory. Therefore, the picnic table discussion was videotaped again with some adjustments to the wording, and more careful attention to the lighting difficulties that presented problems in the first videotaping. This videotape was edited according to the Smokers Group instructions and presented for their approval.

The Nonsmokers Group members approved the edited version of their PSA. The Smokers Group members were satisfied with their PSA, but expressed the wish to add an instrumental music background. After adding music to the Smokers Group PSA, the refined version was shown and approved as an accurate representation of their script. The length of the Smokers Group PSA was 60 seconds, and the length of the Nonsmokers Group PSA was 30 seconds. The scripts for each PSA were transcribed (see Appendix B).

Phase 2: Presentation of the PSAs and Survey of Responses

\section{Questionnaire Construction and Face Validity}

Survey research was conducted to elicit responses from junior high school students to the Smokers Group and Nonsmokers Group PSAs. After many consultations with school officials, communication scholars, health experts, and high school and junior high school students to insure face validity, an instrument was constructed. A great deal of development 
time was spent with high school and junior high school students in particular to assure the wording of the items was comprehensible and natural for that age group. For instance, junior high school-student sons and daughters of friends of the researcher were asked to read the items and respond to them in a dialogue with the researcher. Additionally, two high school teachers invited the researcher to discuss his research project with their classes, during which time he was able to engage in a discussion with the students about the use of questionnaires. During these discussions, the researcher asked the students to comment on the comprehensibility and meaning of the particular items being developed for this study. As a result of these discussions, the researcher made changes in the wording of the items, or actually deleted and added items, according to the recommendations made by the students. For example, after reading two researcher-written items intended to measure a respondent's perception of relevance of the PSA, one of the students suggested a third item, "I can relate to the issues raised in PSA \#1(\#2)," which was incorporated into the questionnaire.

Versions of the questionnaire were also presented to the members of the PSA production groups for their comments on the wording and their understanding of the statements. Some suggestions were made, and were incorporated into the final questionnaire. These individuals stated that they believed the questions, statements, and format were clear, and that, importantly, the multiple items for any one concept would probably elicit the same, or similar, responses. 


\section{Questionnaire Items}

This questionnaire was designed to collect demographic information about the viewers of the PSAs, data regarding their cigarette smoking experience and status, data regarding the smoking experience of their family members and friends, their self-perceptions regarding self-efficacy and risk-taking, and their responses to the PSAs regarding perceived personal relevance and perceived effectiveness of the messages.

Demographics. Items on the questionnaire asked subjects to identify their gender, age, grade, ethnicity, and native language.

Cigarette smoking experience. The subjects were asked questions regarding cigarettes and smoking, including whether they had ever tried smoking cigarettes (smoking experience), and whether they smoke cigarettes now (smoking status).

Psychosocial yariables. Due to the significant differences in psychosocial variables found by Gilchrist, Schinke, and Nurius (1989) when comparing female smokers, female nonsmokers, male smokers, and male nonsmokers, the concepts "self-efficacy" and "risk-taking orientation" were thought to be especially important to measure for this study. Therefore, two statements related to the respondents' perception of "self-efficacy," and five statements related to their "risk-taking orientation" were included in the questionnaire. Each of the self-efficacy and risk-taking statements was followed by a seven-point Likert-type scale, seeking the students' response from "strongly agree" to "strongly disagree." The statements used in the questionnaire were as follows: 


\section{Self-efficacy items}

When my friends and I disagree, I usually end up doing what I want.

I'm usually pretty good at everything I try.

\section{Risk-taking orientation items}

If someone dared me to do something that could be dangerous, I probably would do it.

I might take something from a store without paying for it.

At a party, I might drink enough alcohol to get drunk.

I might skip school if I felt like it.

If someone offered me marijuana, I'd probably smoke it.

The phrasing of the self-efficacy and risk-taking orientation items was based on similar items used in the study done by Gilchrist, Schinke, and Nurius (1989).

Perceived relevance variable. Subjects were asked to respond to three items measuring their perceived relevance for each PSA. Each item was followed by a seven-point Likert-type scale ranging from "strongly agree" to "strongly disagree." The three perceived relevance items were as follows:

Perceived relevance items

PSA \#1(\#2) raised some issues about cigarette smoking that are important to me.

I can relate to the issues raised in PSA \#1(\#2).

PSA \#1(\#2) brought out issues that concern me.

Perceived effectiveness variable. Subjects were asked to respond to six items measuring their perceived effectiveness for each PSA. Each item was followed by a seven-point Likert-type scale ranging from "strongly agree" to "strongly disagree." The six perceived effectiveness items were 
as follows:

Perceived effectiveness items

PSA \#1(\#2) will encourage students not to start smoking.

If I did smoke, even a little, PSA \#1(\#2) would encourage me to stop.

PSA \#1(\#2) will get smokers to think about quitting.

PSA \#1(\#2) will encourage non-smokers to remain

non-smokers.

If I didn't smoke, PSA \#1(\#2) would encourage me not to start. After watching PSA \#1(\#2), smokers may think twice before smoking their next cigarette.

The first PSA shown during any session was called "PSA \#1" and the second PSA was called "PSA \#2." After data entry, recoding was done to rectify the alternate showings of the two PSAs.

Also on the questionnaire were additional items not specifically pertinent to this study, included for possible future analysis. Procedure

Before the questionnaire survey was conducted, the researcher submitted the proposal to the university Human Subjects Committee and was given approval to conduct the research. The student participants were obtained from Social Science classes in a Northern California suburban junior high school. The students were told that the researcher would like their help in evaluating two "don't smoke" PSAs that were created by high school students. A brief discussion was held to ensure that the subjects understood what a PSA was, and the questionnaires were handed out. To ensure anonymity, the subjects were told not to put their names on the questionnaire, that their responses were strictly voluntary, and that no 
subject had to fill out the questionnaire if she or he did not want to.

The subjects first were directed to complete the demographic and smoking experience sections of the questionnaire only. They were then told that they would be shown two PSAs. After watching PSA \#1, they were asked to respond to the statements in the questionnaire about this PSA. Subjects were given about five minutes to record their responses, and then shown PSA \#2. They were then asked to respond to the statements about PSA \#2.

Six showings took place during a period of one day. Each session lasted approximately thirty minutes. The order in which the PSAs were shown was alternated to reduce primacy and/or recency effects. At the end of each session, the questionnaires were collected and placed in separate containers according to the order in which the PSAs had been shown. The researcher thanked the subjects for their participation. 


\section{CHAPTER III}

\section{Findings}

The data were analyzed using a SPSS/PC+ program (Norussis, 1988). First, the responses to the PSAs from subjects shown the Nonsmokers Group PSA as PSA \#1 and the Smokers Group PSA as PSA \#2 were recoded to be consistent with those from subjects who were shown the Smokers Group PSA as PSA \#1 and the Nonsmokers Group PSA as PSA \#2. Second, factor analyses, employing principal component analysis were conducted on the items relating to self-efficacy and risk-taking, on the items requesting responses to the Smokers Group PSA, and on the items requesting responses to the Nonsmokers Group PSA. Third, reliabilities of the individual factors were tested. Fourth, composite scores were formed for the individual factors. Fifth, statistical analyses were conducted to examine the research questions posed at the end of Chapter I.

Specifically, the statistical analyses included dependent t-tests conducted to determine if there were significant differences between mean scores on perceived relevance and/or between mean scores on perceived effectiveness of the two PSAs for female smokers, as well as for females who have experimented with cigarette smoking. ANOVAs were conducted to determine the presence of interaction and/or main effects with regard to gender, smoking experience, and smoking status on the psychosocial variables, perception of self-efficacy and risk-taking orientation, and on the perceived relevance and perceived effectiveness of each of the two PSAs. Finally, multiple regressions were performed to investigate the impact of 
self-efficacy, risk-taking, and perceived relevance on the perceived effectiveness of each of the two PSAs.

\section{Subjects}

To measure responses to the two PSAs, 217 eighth-grade students from the junior high school which is the primary feeder school for the Phase 1 High School were shown the PSAs and asked to complete the questionnaire. Those questionnaires on which subjects did not respond to the question about their smoking experience or smoking status were deleted from the data file, resulting in 206 cases remaining for data analysis. The mean age was 13.75 . There were $103(50 \%)$ females and 103 (50\%) males. Regarding smoking experience, 77 (37.4\%) students indicated that they had tried cigarette smoking, among whom 47 (61.03\%) were female and 30 (38.96\%) were males, while 129 (62.9\%) indicated they had not (56 females, 73 males). Regarding current smoking status, $4.9 \%(n=10)$ of the students indicated they currently were smokers (10 Females, 0 males), and 95.1\% ( $\mathrm{n}=196)$ indicated they were not (93 Females, 103 Males). The two PSAs were shown in six different sessions during one day. Each session was attended by between 26 and 38 students. The order in which the PSAs were shown was alternated to reduce primacy and/or recency effects. The time for each showing and completion of the questionnaire was approximately thirty minutes.

\section{Data Rearrangement}

As the two PSAs were shown in alternating order for each session to reduce primacy and/or recency effects, data from the subjects who viewed 
the Nonsmokers Group PSA first and the Smokers Group FSA second was recoded for consistency. As a result, responses from all subjects to the Smokers Group PSA would be labeled responses to PSA \#1, and all responses to the Nonsmokers Group PSA would be labeled responses to PSA \#2.

\section{Preliminary Findings}

\section{Principal Component Analyses}

To determine if scores from items believed to be associated with each of the two psychosocial variables could be combined to form a composite score for each variable, a principal component analysis was conducted on the two self-efficacy and five risk-taking orientation items (see Table 1). Factors with an eigenvalue greater than 1.0 were extracted. Two factors emerged that accounted for $63.1 \%$ of the variance (see Table 2 ). In order to get a more parsimonious factor structure, a varimax rotation was performed. Items that correlated higher than .40 with a factor were considered to be associated with that factor (see Table 3).

Table 1

Self-efficacy and Risk-taking Orientation Items

SE1 When my friends and I disagree, I usually end up doing what I want.

SE2 I'm usually pretty good at everything I try.

RT1 If someone dared me to do something that could be dangerous, I probably would do it.

RT2 I might take something from a store without paying for it.

RT3 At a party, I might drink enough alcohol to get drunk.

RT4 I might skip school if I felt like it.

RT5 If someone offered me marijuana, I'd probably smoke it.

$$
\overline{\mathrm{SE}}=\text { self-efficacy; } \mathrm{RT} \text { = risk-taking }
$$


Table 2

Factor Analysis of Self-efficacy and Risk-taking Orientation Items

\begin{tabular}{lcccccc}
\hline Variable & Communality & $*$ & Factor & Eigenvalue & Pct of Var & Cum Pct \\
SE1 & .62298 & $*$ & 1 & 3.24042 & 46.3 & 46.3 \\
SE2 & .63697 & $*$ & 2 & 1.17618 & 16.8 & 63.1 \\
RT1 & .44249 & $*$ & & & & \\
RT2 & .64654 & $*$ & & & & \\
RT3 & .75303 & $*$ & & & & \\
RT4 & .65671 & $*$ & & & & \\
RT5 & .65788 & $*$ & & & & \\
\hline
\end{tabular}

Table 3

Rotated Factor Matrix of Self-efficacy and Risk-taking Orientation Items

\begin{tabular}{lll}
\hline & Factor 1 & Factor 2 \\
& & \\
SE1 & .10029 & .78290 \\
SE2 & .07555 & .79452 \\
RT1 & .65386 & .12231 \\
RT2 & .79174 & .14030 \\
RT3 & .86142 & .10479 \\
RT4 & .80731 & .07047 \\
RT5 & .81108 & .00451 \\
\hline
\end{tabular}

The first factor (46.3\% of the variance), composed of RT1, RT2, RT3, RT4, and RT5, dealt with risk-taking orientation, and was labeled Risk-taking. The second factor (16.8\% of the variance), composed of SE1 and SE2, dealt with self-efficacy, and was labeled Self-efficacy.

To determine if scores from items believed to be associated with the perceived relevance and perceived effectiveness variables could be combined to form a composite score for each variable, a second principal component analysis was conducted on the three items related to the viewers' perceptions of relevance, and the six items related to the viewers' 
perceived effectiveness for the Smokers Group PSA (see Table 4). T'wo factors emerged that accounted for $62.6 \%$ of the variance (see Table 5). In order to get a more parsimonious factor structure, a varimax rotation was performed. Items correlated higher than .40 with a factor were considered to be associated with that factor (see Table 6).

Table 4

Perceived Relevance and Effectiveness of Smokers Group PSA Items

SPPR1 PSA \#1 raised some issues about cigarette smoking that are important to me.

SPPR2 I can relate to the issues raised in PSA \#1.

SPPR3 PSA \#1 brought out issues that concern me.

SPEF1 PSA \#1 will encourage students not to start smoking.

SPEF2 PSA \#1 will encourage nonsmokers te remain nonsmokers.

SPEF3 If I did smoke, even a little, PSA \# 1 would encourage me to stop.

SPEF4 If I didn't smoke, PSA \#1 would encourage me not to start.

SPEF5 PSA \#1 will get smokers to think about quitting.

SPEF6 After watching PSA \#1, smokers may think twice before smoking their next cigarette.

SPPR $=$ Perceived relevance $;$ SPEF $=$ perceived effectiveness

Table 5

Factor Analysis of Perceived Relevance and Effectiveness of Smokers Group PSA Items

\begin{tabular}{lcccccc} 
Variable & Communality & $*$ & Factor & Eigenvalue & Pct of Var & Cum Pct \\
& & $*$ & & & & \\
SPPR1 & .57860 & $*$ & 1 & 4.53715 & 50.4 & 50.4 \\
SPPR2 & .65661 & $*$ & 2 & 1.09617 & 12.2 & 62.6 \\
SPPR3 & .68048 & $*$ & & & & \\
SPEF1 & .61662 & $*$ & & & & \\
SPEF2 & .52313 & $*$ & & & & \\
SPEF3 & .70094 & $*$ & & & & \\
SPEF4 & .64753 & $*$ & & & & \\
SPEF5 & .71449 & $*$ & & & & \\
SPEF6 & .51490 & $*$ & & & & \\
\hline
\end{tabular}


Table 6

Rotated Factor Matrix of Perceived Relevance and Effectiveness of Smokers Group PSA Items

\begin{tabular}{lll}
\hline & Factor 1 & Factor 2 \\
SPPR1 & .45385 & .61042 \\
SPPR2 & .13512 & .79837 \\
SPPR3 & .17972 & .80510 \\
SPEF1 & .73575 & .27438 \\
SPEF2 & .71722 & .09349 \\
SPEF3 & .80165 & .24145 \\
SPEF4 & .78214 & .18918 \\
SPEF5 & .82190 & .19742 \\
SPEF6 & .65747 & .28747 \\
\hline
\end{tabular}

The first factor (50.4\% of the variance,) composed of items SPEF1, SPEF2, SPEF3, SPEF4, SPEF5, and SPEF6, dealt with the viewers' perceived effectiveness of the Smokers Group PSA, and was labeled Smokers PSA Perceived Effectiveness. The second factor (12.2\% of the variance) was composed of items SPPR1, SPPR2, and SPPR3, intended to measure the viewers' perception of relevance for Smokers Group PSA, and was, therefore, labeled Smokers PSA Perceived Relevance. Although there was double loading on one item, SPPR1, it was loaded more highly with the Smokers Group PSA Perceived Relevance Factor and so assumed to be associated with that factor.

To determine if scores from items believed to be associated with the perceived relevance and perceived effectiveness variables could be combined to form a composite score for each variable, a third principal component analysis was conducted on the three items intended to measure the viewers' perceptions of relevance, and the six items intended to 
measure the viewers' perceived effectiveness for the Nonsmokers Group PSA (see Table 7). Two factors emerged that accounted for $60.5 \%$ of the variance (see Table 5). In order to get a more parsimonious factor structure, a varimax rotation was performed. Items correlated higher than .40 with a factor were considered to be associated with that factor (see Table 6).

Table 7

Perceived Relevance and Effectiveness of Nonsmokers Group PSA Items

NPPR1 PSA \#2 raised some issues about cigarette smoking that are important to me.

NPPR2 I can relate to the issues raised in PSA \#2.

NPPR3 PSA \#2 brought out issues that concern me.

NPEF1 PSA \# will encourage students not to start smoking.

NPEF2 PSA \#2 will encourage nonsmokers to remain nonsmokers.

NPEF3 If I did smoke, even a little, PSA \#2 would encourage me to stop.

NPEF4 If I didn't smoke, PSA \$2 would encourage me not to start.

NPEF5 PSA \#2 will get smokers to think about quitting.

NPEF6 After watching PSA \#2, smokers may think twice before smoking their next cigarette.

NPPR = perceived relevance; NPEF = perceived effectiveness

Table 8

Factor Analysis of Perceived Relevance and Effectiveness of Nonsmokers Group PSA Items

\begin{tabular}{lrrrccr}
\hline Variable & Communality & $*$ & Factor & Eigenvalue & Pct of Var & Cum Pct \\
NPPR1 & .61919 & $*$ & 1 & 4.17698 & 46.4 & 46.4 \\
NPPR2 & .59376 & $*$ & 2 & 1.26934 & 14.1 & 60.5 \\
NPPR3 & .58924 & $*$ & & & & \\
NPEF1 & .61056 & $*$ & & & & \\
NPEF2 & .63048 & $*$ & & & & \\
NPEF3 & .65051 & $*$ & & & & \\
NPEF4 & .64953 & $*$ & & & & \\
NPEF5 & .58379 & $*$ & & & & \\
NPEF6 & .51925 & $*$ & & & & \\
\hline
\end{tabular}


Table 9

Rotated Factor Matrix of Perceived Relevance and Effectiveness of Nonsmokers Group PSA Items

\begin{tabular}{lrl}
\hline & Factor 1 & Factor 2 \\
NPPR1 & .28820 & .73221 \\
NPPR2 & -.05481 & .76861 \\
NPPR3 & .27956 & .71490 \\
NPEF1 & .75896 & .18585 \\
NPEF2 & .79352 & .02844 \\
NPEF3 & .69940 & .40169 \\
NPEF4 & .80446 & .04871 \\
NPEF5 & .59710 & .47672 \\
NPEF6 & .64705 & .31713 \\
\hline
\end{tabular}

The first factor (46.4\% of the variance,) composed of items NPEF1, NPEF2, NPEF3, NPEF4, NPEF5, and NPEF6, dealt with the viewers' perceived effectiveness of the Nonsmokers Group PSA, and was labeled Nonsmokers PSA Perceived Effectiveness. The second factor (12.2\% of the variance) was composed of items NPPR1, NPPR2, and NPPR3, items intended to measure the viewers' perception of relevance for Nonsmokers Group PSA, and was labeled Nonsmokers PSA Perceived Relevance. Although two items, NPEF3 and NPEF5, were double loaded, they were more highly associated with the Nonsmokers Group PSA Perceived Effectiveness factor, and so assumed to be items related to that factor. $\underline{\text { Reliabilities }}$

The reliabilities of the self-efficacy and risk-taking items were tested, respectively. Reliability of the two self-efficacy items was deemed unacceptable (alpha $=.42$ ), and the factor identified as Self-efficacy was eliminated from further analyses. Reliability of the five risk-taking items 
was considered acceptable (alpha=.85). The reliabilities of the Smokers Group PSA items measuring perceived relevance and perceived effectiveness were also tested. Reliability for the three Smokers Group PSA perceived relevance items was acceptable (alpha $=.68$ ), as was the reliability for the six Smokers Group PSA perceived effectiveness items (alpha=.88). The reliabilities of the Nonsmokers Group PSA items measuring perceived relevance and perceived effectiveness were computed. Reliability for the three Nonsmokers Group PSA perceived relevance items was considered acceptable (alpha=.67), as was the reliability for the five Nonsmokers Group PSA perceived effectiveness items (alpha $=.86$ ).

Composite Variables

Because of the emergence of factors from items measuring risk-taking, perceived relevance and perceived effectiveness for the Smokers Group PSA, and perceived relevance and perceived effectiveness for the Nonsmokers Group PSA, and the acceptable levels of reliabilities, composite scores were computed for each. Risk-taking scores were computed by adding the seven items and labeled Risk. Perceived relevance scores and perceived effectiveness scores for the Smokers Group PSA were computed and labeled SPRELE and SPEFFECT, respectively. Perceived relevance scores and perceived effectiveness scores for the Nonsmokers Group PSA were computed and labeled NPRELE and NPEFFECT, respectively. 
Research Findings

Significance of Mean Differences for Select Groups

To explore Research Questions 1 and 2, dependent t-tests were conducted with the selected groups "female cigarette smokers" and "females who have tried smoking" to determine if the means for perceived relevance and/or perceived effectiveness of the two PSAs were significantly different. "Female cigarette smokers" includes those subjects who indicated on the questionnaire that they currently smoke cigarettes, and "females who have tried smoking" was comprised of those females who indicated that they have experimented with cigarette smoking, including those who currently smoke. The results are presented in Tables 10 and 11.

Table 10

Paired t-tests. Perceived Relevance of Smokers Group and Nonsmokers Group PSAs

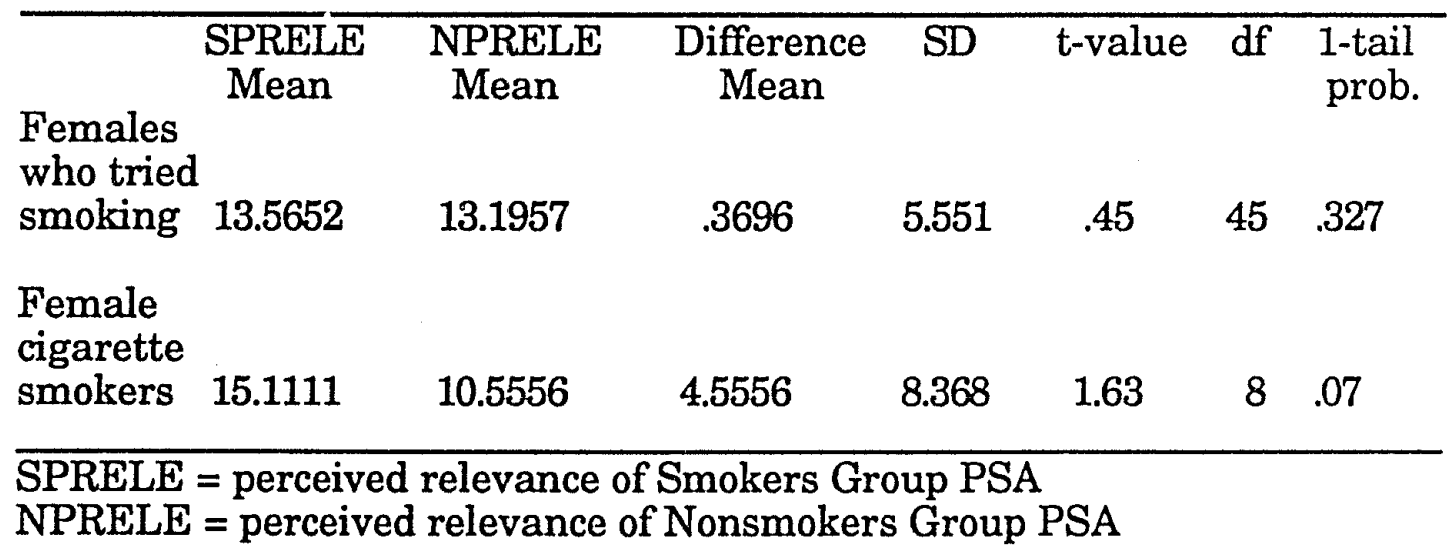


Table 11

Paired t-tests. Perceived Effectiveness of Smokers Group and Nonsmokers Group PSAs

\begin{tabular}{|c|c|c|c|c|c|c|c|}
\hline & SPEFFECI & NPEFFECT & Difference & SD & t-value & $\mathrm{df}$ & 1-tail \\
\hline $\begin{array}{l}\text { Females } \\
\text { who tried } \\
\text { smoking }\end{array}$ & 28.6957 & 24.5435 & 4.1522 & 9.787 & 2.88 & 45 & .003 \\
\hline $\begin{array}{l}\text { Female } \\
\text { cigarette } \\
\text { smokers }\end{array}$ & 26.6000 & 21.2000 & 5.4000 & 15.357 & 1.11 & 9 & .15 \\
\hline
\end{tabular}

Regarding perceived relevance, there was no significant difference between the two PSAs for females who have tried cigarette smoking. For females who currently smoke cigarettes, perceived relevance of the Smokers Group PSA was greater than that of the Nonsmokers Group PSA (15.1111 vs. 10.5556 ), but this difference only approached significance at the .05 level $(Q=.07)$.

Regarding perceived effectiveness, there was a significant difference between the two PSAs for females who have tried smoking. The females who have tried cigaratte smoking perceived the Smokers Group PSA as more effective than the Nonsmokers Group PSA (28.6957 vs. $24.5435, \underline{p}=$ .003). There was no significant difference in perceived effectiveness of the two PSAs for females who currently smoke cigarettes.

\section{Analyses of Variance}

Research Questions 3a and 3b were to be explored by conducting ANOVAs to test for interaction and main effects for gender (SEX) and 
smoking experience (EXP), and for gender (SEX) and smoking status (STATUS) on the psychosocial variables risk-taking orientation (Risk) and perception of self-efficacy (Self-efficacy). Since the self-efficacy items did not reach an acceptable level of reliability, only the risk-taking orientation factor was used for these ANOVA analyses. Smoking experience refers to whether the subject has ever experimented with cigarette smoking (yes or no), and smoking status refers to whether the subject currently is a cigarette smoker (yes or no).

Significant main effects were found for both smoking experience ( $\underline{F}$ $[1,195]=57.548, \mathfrak{p}<.001)$ and smoking status $(\mathbb{F}[1,196]=18.264, \mathrm{D}<.001)$ on risk-taking, with those who have tried smoking scoring higher $(18.24, \underline{\mathrm{n}}=$ 74) than those who have not $(10.54, \underline{n}=125)$, and those who currently smoke scoring higher $(24.22, \underline{n}=9)$ than those who do $\operatorname{not}(12.89, \underline{n}=190)$ (see Tables 12 and 13). Interaction effects for gender and smoking experience only approached significance $(E[1,195]=3.321, \mathrm{p}=.07)$ with females who have tried smoking scoring highest on the Risk-taking score $(19.27, \underline{\mathrm{n}}=45)$, females who have not tried smoking scoring lowest $(9.93, \underline{n}=55)$, and males who have and have not tried falling in between $(16.66, \underline{n}=29$ and $11.01, \mathrm{n}=70$, respectively). 
Table 12

ANOVA: Risk-taking by Smoking Experience and Gender

\begin{tabular}{lrrrrr}
\hline $\begin{array}{l}\text { Source of } \\
\text { Variation }\end{array}$ & $\begin{array}{c}\text { Sum of } \\
\text { Squares }\end{array}$ & $\mathrm{df}$ & $\begin{array}{c}\text { Mean } \\
\text { Square }\end{array}$ & $\mathrm{F}$ & $\begin{array}{c}\text { Signif } \\
\text { of } \mathrm{F}\end{array}$ \\
\hline Main Effects & 2764.394 & 2 & 1382.197 & 29.927 & $<.001$ \\
$\quad \begin{array}{l}\text { Experience } \\
\text { Sex }\end{array}$ & 2657.865 & 1 & 2657.865 & 57.548 & $<.001$ \\
& 3.264 & 1 & 3.264 & .071 & .791 \\
$\begin{array}{l}\text { 2-way } \\
\text { Interactions }\end{array}$ & 153.399 & 1 & 153.399 & 3.321 & .070 \\
Exp. Sex & 153.399 & 1 & 153.399 & 3.321 & .070 \\
& & & & & \\
Explained & 2917.793 & 3 & 972.598 & 21.059 & $<.001$ \\
Residual & 9006.047 & 195 & 46.185 & & \\
Total & 11923.839 & 198 & 60.221 & & \\
\hline
\end{tabular}

Table 13

ANOVA: Risk-taking by Smoking Status and Gender

\begin{tabular}{lrrrrr}
\hline $\begin{array}{l}\text { Source of } \\
\text { Variation }\end{array}$ & $\begin{array}{c}\text { Sum of } \\
\text { Squares }\end{array}$ & $\mathrm{df}$ & $\begin{array}{c}\text { Mean } \\
\text { Square }\end{array}$ & $\mathrm{F}$ & $\begin{array}{c}\text { Signif } \\
\text { of } \mathrm{F}\end{array}$ \\
\hline Main Effects & 1113.866 & 2 & 556.933 & 10.098 & $<.001$ \\
$\begin{array}{l}\text { Status } \\
\text { Sex }\end{array}$ & 1007.337 & 1 & 1007.337 & 18.264 & $<.001$ \\
& 10.261 & 1 & 10.261 & .186 & .661 \\
Explained & 1113.866 & 2 & 556.933 & 10.098 & $<.001$ \\
Residual & 10809.973 & 196 & 55.153 & & \\
Total & 11923.839 & 198 & 60.221 & & \\
\hline
\end{tabular}

To investigate Research Questions 4a and 4b, ANOVAs were conducted to determine main effects and/or interaction effects for gender (SEX) and smoking experience (EXP), and for gender (SEX) and smoking status (STATUS) on perceived relevance and perceived effectiveness of the 
Smokers Group PSA (SPRELE and SPEFFECT), and perceived relevance and perceived effectiveness of the Nonsmokers Group PSA (NPRELE and NPEFFECT).

No significant effects were found for gender, experience, or status on perceived relevance or effectiveness for the Smokers Group PSA.

Main effects were found for gender on perceived relevance of the Nonsmokers Group PSA ( $F[1,191]=5.094, \mathrm{p}<.05)$ with females indicating significantly higher perceived relevance than males $(13.14, \underline{\mathrm{n}}=100$ vs. 11.84 , $\underline{n}=95$ ) for that PSA (see Table 14). Significant main effects were also found for smoking experience on perceived effectiveness of the Nonsmokers Group PSA $(\mathrm{E}[1,191]=7.060, \mathfrak{p}<.01)$ with those who have not tried smoking perceiving the Nonsmokers Group PSA to be more effective than those who have tried smoking $(27.21, \underline{n}=123$ vs. $24.39, \underline{n}=72)$ (see Table 15 ).

Table 14

ANOVA: Perceived Relevance of Nonsmokers Group PSA by Smoking Experience and Gender

\begin{tabular}{lrrrrr}
\hline $\begin{array}{l}\text { Source of } \\
\text { Variation }\end{array}$ & $\begin{array}{c}\text { Sum of } \\
\text { Squares }\end{array}$ & df & $\begin{array}{c}\text { Mean } \\
\text { Square }\end{array}$ & F & $\begin{array}{c}\text { Signif } \\
\text { of F }\end{array}$ \\
\hline Main Effects & 82.423 & 2 & 41.212 & 2.697 & .070 \\
$\quad$ Experience & .356 & 1 & .356 & .023 & .879 \\
$\quad$ Sex & 77.828 & 1 & 77.828 & 5.094 & .025 \\
2-way & & & & & \\
Interactions & .214 & 1 & .214 & .014 & .906 \\
Exp. Sex & .214 & 1 & .214 & .014 & .906 \\
$\begin{array}{l}\text { Explained } \\
\text { Residual }\end{array}$ & 82.638 & 3 & 27.546 & 1.803 & .148 \\
Total & 2918.101 & 191 & 15.278 & & \\
\hline
\end{tabular}


Table 15

ANOVA: Perceived Effectiveness of Nonsmokers Group PSA by Smoking Experience and Gender

\begin{tabular}{lrrrrr}
\hline $\begin{array}{l}\text { Source of } \\
\text { Variation }\end{array}$ & $\begin{array}{l}\text { Sum of } \\
\text { Squares }\end{array}$ & $\mathrm{df}$ & $\begin{array}{c}\text { Mean } \\
\text { Square }\end{array}$ & $\mathrm{F}$ & $\begin{array}{c}\text { Signif } \\
\text { of } F\end{array}$ \\
\hline Main Effects & 363.582 & 2 & 181.781 & 3.745 & .025 \\
$\quad \begin{array}{l}\text { Experience } \\
\text { Sex }\end{array}$ & 342.644 & 1 & 342.644 & 7.060 & .009 \\
& 1.761 & 1 & 1.761 & .036 & .849 \\
2-way & & & & & \\
Interactions & 35.969 & 1 & 35.969 & .741 & .390 \\
Exp. Sex & 35.969 & 1 & 35.969 & .741 & .390 \\
& & & & & \\
Explained & 399.531 & 3 & 133.177 & 2.744 & .044 \\
Residual & 9269.885 & 191 & 48.533 & & \\
Total & 9669.415 & 194 & 49.842 & & \\
\hline
\end{tabular}

Main effects were found for gender and smoking status on the perceived relevance of the Nonsmokers Group PSA, where females perceived the Nonsmokers Group PSA to be more relevant than males $(13.14, \underline{\mathrm{n}}=100$ vs. $11.84, \underline{\mathrm{n}}=95, \underline{\mathrm{F}}[1,192]=7.550, \underline{\mathrm{g}}<.01)$ and nonsmokers perceived the Nonsmokers Group PSA to be more relevant than smokers $(12.60, \underline{\mathrm{n}}=186$ vs. $10.56, \underline{\mathrm{n}}=9, \underline{\mathrm{F}}[1,192]=4.446, \underline{\mathrm{p}}<.05)$ (see Table 16$)$. It was not possible to determine interaction effects for gender and smoking status because of the absence of male smokers.

Perceived effectiveness of the Nonsmokers Group PSA only approached significance $(\mathrm{E}[1,192]=3.138, \mathfrak{Q}=.078)$ with nonsmokers perceiving the Nonsmokers Group PSA to be more effective than smokers $(26.38, \underline{\mathrm{n}}=186$ vs. $21.89, \underline{\mathrm{n}}=9)$ (see Table 17$)$. 
Table 16

ANOVA: Perceived Relevance of Nonsmokers Group PSA by Smoking Status and Gender

\begin{tabular}{lrrrrr}
\hline $\begin{array}{l}\text { Source of } \\
\text { Variation }\end{array}$ & $\begin{array}{c}\text { Sum of } \\
\text { Squares }\end{array}$ & $\mathrm{df}$ & $\begin{array}{c}\text { Mean } \\
\text { Square }\end{array}$ & $\mathrm{F}$ & $\begin{array}{c}\text { Signif } \\
\text { of } \mathrm{F}\end{array}$ \\
\hline Main Effects & 148.126 & 2 & 74.063 & 4.985 & .008 \\
$\quad \begin{array}{l}\text { Status } \\
\text { Sex }\end{array}$ & 66.060 & 1 & 66.060 & 4.446 & .036 \\
& 112.169 & 1 & 112.169 & 7.550 & .007 \\
$\begin{array}{l}\text { Explained } \\
\text { Residual }\end{array}$ & 148.126 & 2 & 74.063 & 4.985 & .008 \\
Total & 2852.612 & 192 & 14.857 & & \\
\hline
\end{tabular}

Table 17

ANOVA: Perceived Effectiveness of Nonsmokers Group PSA by Smoking Status and Gender

\begin{tabular}{lrrrrr}
\hline $\begin{array}{l}\text { Source of } \\
\text { Variation }\end{array}$ & $\begin{array}{c}\text { Sum of } \\
\text { Squares }\end{array}$ & df & $\begin{array}{c}\text { Mean } \\
\text { Square }\end{array}$ & F & $\begin{array}{c}\text { Signif } \\
\text { of F }\end{array}$ \\
\hline Main Effects & 176.098 & 2 & 88.049 & 1.781 & .171 \\
$\quad$ Status & 155.180 & 1 & 155.180 & 3.138 & .078 \\
$\quad$ Sex & 3.227 & 1 & 3.227 & .065 & .799 \\
& & & & & \\
Explained & 176.098 & 2 & 88.049 & 1.781 & .171 \\
Residual & 943.318 & 192 & 49.444 & & \\
Total & 9669.415 & 194 & 49.842 & & \\
\hline
\end{tabular}

\section{Regression Analyses}

To explore Research Question 5, the two factors Risk and Perceived Relevance were used as predictor variables for the factor Perceived Effectiveness for both the Smokers Group PSA and Nonsmokers Group PSA. Once again, the factor Self-efficacy was not used due to the 
unacceptable reliability of the the self-efficacy items.

Perceived Effectiveness of the Smokers Group PSA was significantly predicted by both Risk and Perceived Relevance $\left(\underline{R}=.629, \underline{R}^{2}=.396, \underline{F}[2,191]\right.$ $=62.64, \mathrm{Q}<.001)$. Subsequent $\mathrm{t}$ tests indicated that $\operatorname{Risk}(\beta=-.198, \mathrm{t}[1,192]=$ $-3.50, \mathrm{D}<.001)$, and Perceived Relevance $(\beta=.618, \mathrm{t}[1,192]=10.932, \mathrm{D}<.001)$ were significant predictors of Perceived Effectiveness of the Smokers Group PSA. The more the subject was a risk taker, the less effective she or he perceived the PSA to be. The more relevant the PSA was perceived, the more persuasive/effective it was perceived.

Perceived Effectiveness of the Nonsmokers Group PSA was also significantly predicted by both Risk and Perceived Relevance $\left(\underline{R}=.584, \underline{R}^{2}=\right.$ $.342, \underline{\mathrm{F}}[2,193]=50.16, \mathrm{D}<.001)$. Subsequent $\mathrm{t}$ tests indicated that Risk $(\beta=$ $-.309, \mathrm{t}[1,194]=-5.03, \mathrm{Q}<.001)$, and Perceived Relevance $(\beta=.50, \mathrm{t}[1,194]=$ $8.57, \mathfrak{p}<.001$ ) were significant predictors of Perceived Effectiveness of the Nonsmokers Group PSA. The higher the subject scored as a risk taker, the less effective she or he perceived the PSA to be. The more the subject perceived the PSA to be relevant, the more she or he perceived it to be persuasive/effective. 


\section{CHAPTER IV}

\section{Discussion}

The goal of this study was to extend the research in persuasive communication by examining the impact of perceived message relevance on the processing and evaluation of persuasive messages. Petty and Cacioppo (e.g., 1979, 1984, 1986) have demonstrated that increased relevance can enhance the effectiveness of persuasive messages. Since female adolescent smokers have demonstrated a high degree of resistance to smoking deterrence programs, the goal of this study was to create and test a "don't smoke" message that might be perceived with more relevance by female adolescent smokers. The expectation was that message relevance could be increased when a message is created by representative members of the intended audience; individuals who can and are inclined to address particular concerns and interests that are most relevant for that particular population regarding a particular issue.

Specifically, female adolescents who smoke cigarettes should be the best resource for creating messages that are perceived with a high degree of relevance by both female adolescents who smoke cigarettes, and female adolescents who have indicated an inclination to become regular cigarette smokers. To test this notion, two videotaped PSAs were created; one by female adolescent smokers, and one by female adolescent nonsmokers. These two PSAs were shown to audiences comprised of, in part, female adolescents who indicated that they currently smoke, or have experimented with cigarette smoking. Their responses were used to 
explore the research questions asked at the end of Chapter I.

\section{Research Question 1}

Research Question 1a asked if female adolescents who currently smoke cigarettes might perceive a "don't smoke" message created by female adolescents who smoke as more relevant than one created by female adolescents who don't smoke. The results show that, for female smokers, the Smokers Group PSA was more relevant than the Nonsmokers Group PSA, but this difference only approached significance ( 15.1111 vs. $10.5556, \mathfrak{p}=.07$ ). Although the results are not robust, they suggest a difference that should be explored further, ideally with a greater number of female adolescent smokers than the number participating in this study $(n=10)$.

Research Question $1 \mathrm{~b}$ asked if female adolescents who currently smoke cigarettes might perceive a "don't smoke" message created by female adolescents who smoke as more effective than one created by female adolescents who don't smoke. Although the female adolescent smokers indicated greater perceived effectiveness for the Smokers Group PSA than for the Nonsmokers Group PSA (26.6 vs. 21.2), the difference failed to reach significance $(2=.15)$. As in the perceived relevance finding for this group of subjects, though shy of significance, the finding in the expected direction is encouraging and supports the need for more research in this area, hopefully with a larger pool of subjects.

The mixed findings relative to Research Question 1, that the relevance items approached significance and the effectiveness items did 
not, raises concerns that warrant consideration. One concern stems from the fact that this study used perceived effectiveness rather than actual effectiveness as a dependent variable. While the relevance items required subjects simply to indicate to what extent they personally relate to the content of the messages, the perceived effectiveness items asked subjects to make predictions about the potential effectiveness of a message. One possible explanation for the mixed results is that the female adolescent smoker respondents may be eager and able to express how they feel about the content of "don't smoke" messages, but more reluctant to predict and compare the potential effectiveness of these messages. If so, it may help explain why they responded to the two PSAs somewhat differently on subjective items, e.g., items that dealt with personal relevance, but not so differently on the more objective items, e.g., items regarding perceived effectiveness.

The limited nature of this study required that perceived effectiveness be used as a variable rather than actual effectiveness. A more encompassing study might be one that would attempt to measure actual effectiveness, perhaps by repeating the experimental conditions over time, and measuring subjects' attitudes and behaviors on a number of occasions during that time.

A second concern that puts the quality of the findings at jeopardy stems from the extremely small subject pool of female adolescent smokers. Although smoking intervention program professionals identify female adolescent smokers as a high-risk group, particularly resistant to 
intervention efforts, they are still a relatively small percentage of the adolescent population. This fact makes it difficult to identify and isolate enough subjects, especially during the age of smoking initiation, in order to conduct population sample research that can produce generalizable findings. It is hoped that future research would involve larger populations of female adolescent smokers through broader based studies, perhaps incorporating an entire school district rather than a single school.

There is heuristic value in the finding that the Smokers Group PSA approached a significantly greater degree of perceived relevance than the Nonsmokers Group PSA for female adolescent smokers. The results tentatively support the position that message relevance is likely to be greater when the message is created by individuals with a similar type and degree of involvement with the issue as the intended audience. That perceived effectiveness did not differ significantly between the two PSAs does not diminish that value. However, considering that the relationship between relevance and effectiveness is one of the central concerns of this study, the potential confounding effect of perceived effectiveness and actual effectiveness is one that needs addressing in future studies. As suggested above, actual effectiveness might be measured more accurately by using issue-attitude and behavioral measures, especially if done in a longitudinal study with a larger pool of female adolescent smokers, perhaps providing a clearer picture of the relationship between perceived relevance and message effectiveness. 


\section{Research Question 2}

Research Question 2a asked if female adolescents who have experimented with cigarette smoking might perceive more relevance in a "don't smoke" message created by female adolescent smokers than in one created by female adolescent nonsmokers. The results show no significant differences in terms of perceived relevance. It is possible that this failure to produce differences may be explained by the more heterogeneous make-up of such a group. "Females who have tried smoking" may include those who have taken one puff of a friend's cigarette, as well as individuals who "experiment" weekly but do not characterize themselves as smokers. This being the case, it is difficult to make assumptions about the level or quality of experience with cigarette smoking these individuals have had, not to mention how these differences influence their perceptions of relevance in a persuasive message.

That being said, the results addressing Research Question $2 \mathrm{~b}$ present a quandary. The members of this group, female adolescents who have tried smoking, perceived the Smokers Group PSA to be significantly more effective than the Nonsmokers Group PSA. One reason that may explain why this occurred is that, while the members of this group did not personally perceive one PSA.as more relevant than the other, they simply believed, perhaps from their association with cigarette smokers, that the Smokers Group PSA message would be more effective with those who are more at-risk for becoming cigarette smokers. In other words, although the experimenters did not find the Smokers Group PSA more personally 
relevant, from their experience with cigarette smoking they believed that they could predict greater effectiveness for that PSA.

Research Question 3

Research Question 3 explored the differences in the psychosocial variables risk-taking and self-efficacy in terms of gender, experimental cigarette smoking, and current cigarette smoking. Due to the unacceptable reliability of items measuring self-efficacy, this variable was not tested. For risk-taking, there were no significant differences in terms of gender. However, risk-taking was significantly associated with both experimentation and adoption of cigarette smoking. This finding supports the research by Gilchrist, Schinke, and Nurius (1989) who found a significantly higher degree of risk-taking in adolescent girls who smoke vs. those who do not smoke, and supports their argument that this important distinction must be considered when developing intervention efforts intended for female adolescent smokers.

Research Question 4

Research Question 4a asked how group membership in terms of gender, smoking experience, and smoking status might influence perceptions of relevance of the two PSAs. No significant findings resulted for the Smokers Group PSA. For the Nonsmokers Group PSA, main effects were found for gender, with females perceiving this PSA as more relevant than males. One might expect that, if one PSA was perceived as more relevant by females than by males, both PSAs would be perceived as more relevant by females than by males, since both were created by 
females. It is unclear why this occurred, and suggests the need for further investigation into how and why different subjects respond differently to messages having the same general intent.

Research Question $4 \mathrm{~b}$ asked how group membership in terms of gender, smoking experience, and smoking status would influence perceptions of effectiveness of the two PSAs. As in Research Question 4a, no significant differences were found in responses to the Smokers Group PSA. In responding to the Nonsmokers Group PSA, no significant effects were found for gender on perceived effectiveness, but significant effects were found for experience. Subjects who indicated they have never tried cigarette smoking perceived the Nonsmokers PSA as more effective than those who have experimented with smoking. This finding is not surprising, even though there were no perceived differences in terms of relevance for this group. Although the subjects who have never tried smoking may find neither PSA relevant for themselves, they apparently believe that the message created by nonsmokers will be more effective than do the smoking experimenters; perhaps because that message most clearly reflects their own beliefs about cigarette smoking and smokers.

Those subjects who indicated that they do not currently smoke cigarettes also perceived the Nonsmokers Group PSA to be more effective than did subjects who do currently smoke, although this difference only approached significance $(\mathrm{z}=.078)$. Those who do not currently smoke, the majority of whom have never tried smoking, are similar to those who have never tried smoking in their belief that the Nonsmokers Group PSA 
reflects their own opinions about why people shouldn't smoke. At the same time, the fact that the results only approached significance for current nonsmokers while the results for those who have never smoked were highly significant may be due to the fact that some of the current nonsmokers have experimented with cigarette smoking in the past and, from that experience, are more reserved about making predictions about effectiveness of any "don't smoke" messages.

\section{Research Question 5}

Research Question 5 asked how perceptions of relevance and the degree of the psychosocial variables of risk-taking and self-efficacy might serve as predictors of perceived effectiveness. Self-efficacy was removed from the analysis due to low reliability scores for this factor's items. Both risk-taking and perceived relevance demonstrated high predictive power, individually and collectively, for perceived effectiveness for both PSAs; risk-taking in a negative direction, and perceived relevance in a positive direction. This finding shows the important role each of these variables plays in the potential effectiveness of persuasive messages. The higher the risk-taking orientation of the individual, the less likely that individual believes a persuasive message will move her or him to a contrary position. However, the more relevant that individual perceives the message, the more likely that message will move her or him to a contrary position.

The negative relationship between risk-taking orientation and perception of effectiveness is especially important when we take into consideration the relationship between risk-taking orientation and 
likelihood to experiment with or adopt cigarette smoking. That is, the subjects who are inclined to smoke are those who scored highest on the risk-taking scores; the very ones smoking intervention program designers are trying to influence. Coupled with the positive relationship discovered between perceived relevance and perceived effectiveness, this finding demonstrates the importance of increasing the perceived relevance for those subjects who are highly risk-taking oriented.

Petty and Cacioppo (1990) have emphasized that perceived relevance alone did not increase effectiveness of persuasive messages. They argue that perceived relevance interacts with other variables to mediate the effectiveness of these messages; in this study, we see how perceived relevance and risk-taking orientation interact to predict perceptions of effectiveness. This result suggests that relevance becomes an even more important concern when trying to influence a group with a high risk-taking orientation; a condition that seems to prevail among those inclined to become cigarette smokers.

These findings, along with the mixed results in the findings for Research Questions 1, 2, and 4 suggest that the continuous variables of risk-taking and perceived relevance are more powerful predictors of perceived effectiveness than the categorical variables of gender, experience, or status. The implications from these results include the potentially greater value of categorizing individuals by the psychosocial differences that may be associated with high-risk behavior, räutıer than the more common approach of categorizing people by their actual behavior. It 
is possible, for example, that some or many of the members of the group "femaies who have tried smoking" are not high-risk individuals. If we are trying to influence the real high-risk individuals, we need to focus our efforts on identifying what is most relevant for them, not what is relevant for anyone who may have dabbled in high-risk activity. Perhaps future research could explore the differences in perceived message relevance for high risk-taking individuals of messages created by persons rating either high or low on a risk-taking scale.

\section{Characteristics of the PSAs}

Distinctions exist between the PSAs created by the two groups that deserve some discussion. While these distinctions may be difficult to quantify, this researcher's subjective observations are meant to raise issues for further research rather than to pose them as findings.

Although members of both groups expressed the desire not to tell potential smokers what to do, the resulting tone of each PSA is worth noting. The Smokers Group members chose to express their own qualms about being smokers in a discussion setting, whereas the members of the Nonsmokers Group chose to make a more assertive statement, however subtly couched in a series of rhetorical questions suggesting hypocrisy in smokers who claim to be concerned about poilution. This difference illustrates an awareness the smokers have of the situation in which they find themselves, and an empathy for smokers that may be difficult for nonsmokers to possess. The Smokers Group presented themselves as victims, albeit by their own hands, while the Nonsmokers Group 
represented smokers as witting perpetrators of contrary behavior. The Smokers Group PSA seemed to invite the audience to learn from the smokers' mistakes, while the Nonsmokers Group PSA had a lesson to teach. These differences infuse each group's bias and agenda into the nonverbal elements of the messages, read between the lines by the intended audience. These messages tell the viewers things about the source of the message and the intentions of the messenger that may make the difference in how the viewers evaluate the content, as well as the relevance, of the message.

Research with Adolescents in the School Environment

Since this study involved adolescents, and since the most efficient way to recruit adolescents was in the school system, some thoughts about research as it concerns adolescents and school systems may be useful both to educators and to future researchers who hope to do research with these subjects in this environment.

As was discussed in Chapter II, this researcher found it very difficult to pursue the field experimental plan. While individual administrators and teachers expressed tentative interest in the research, their overriding concerns for the in-place structure and agenda of the school system made implementation of the project seem burdensome.

Ultimately, this project was able to proceed due to the strong commitment of one respected administrator with a can-do attitude, working with other administrators and faculty who saw value in the study; value in the potential findings and, more importantly, value for the 
students who would participate. As Student Liaison Officer, this administrator interacts with students who have run afoul of school rules, such as smoking on campus, and was genuinely interested in helping his charges make "healthy choices." In addition, and as important, this administrator displayed a warm rapport with the students, and he was able to approach students who might be interested in participating without their feeling pressured to do so.

The project also required commitment and flexibility on the part of all parties: the principal provided a conference room in which the focus groups could meet; teachers allowed students to miss a couple of classes for some meetings; students dedicated several lunch hours to meet. The end result of this commitment and flexibility was an experience that enriched the education of the participants, both smokers and nonsmokers. Through focus group meetings, these students collaborated in developing and producing a media-message: they were called upon as the experts, they accepted the responsibility for the task, and they shared pride in the solution. The final product, the videotaped PSA, is evidence of their commitment and collaboration.

Although the stated purpose of this study was to explore ways to increase the relevance of messages, an integral objective was to recognize and affirm the value of contributions that can be made by those who are usually on the receiving end of pedagogy, whether they be cigarette smokers or high school students. The researcher believes that this objective was met, and that the study was, thereby, enriched. 
The discussions held with the adolescent participants were eye opening, providing the researcher with an opportunity to improve his own intergenerational communication skills. Each resulting PSA was original and carried a strong sense of its adolescent producers, a feeling that could not have been created by any adult. Perhaps this study will encourage researchers to venture out beyond the college classroom, and public school administrators and teachers to welcome such research into their environment. It is hoped also that this study will help persuade educators to think of some of their "problem students" as potential problem solvers.

Conclusion and Recommendations

This study was an effort to explore ways to help people. Individuals like cigarette smokers at one time, before they became addicted, made a choice to adopt a behavior that is harmful to themselves, their families, and their friends, as well as costly to society. Efforts to intervene with the decision to become a smoker depend on becoming more knowledgeable in communicating messages that are not ignored or rejected. Increasing message relevance is likely to encourage more attention to the message. Increasing message relevance is more likely to be accomplished by acknowledging and addressing differences between smokers and nonsmokers, as well as differences found among smokers themselves. The psychosocial differences discussed by Gilchrist, Schinke, and Nurius (1989) and the motivational differences identified by Glynn, Leventhal, and Hirschman (1985) both confirm the complexity of human behavior and recommend a direction for future research into what makes a message 
relevant.

Furthermore, communication researchers need to distinguish between issue relevance and message relevance. Too much is assumed about the transfer of perceived relevance from issue importance to message relevance. The messages themselves need to be considered to determine if they hold relevance for the receiver as they are being received. It has been argued and supported by the research that issue relevance influences the way individuals process messages. More research needs to explore how the perceived relevance of the content of the message itself impacts on the way individuals process that message.

Finally, future research into message relevance and persuasive communication should focus more on intimate issues; issues that directly impact individuals in personally consequential ways, as well as require the individuals to make choices that will change those consequences. Smoking is such an issue, as are other substance abuse issues. But other issues such as prejudice, vandalism, violence; these too may be thought of as behaviors that are harmful to the individual, the family, and the society. These too may have been chosen by individuals as useful and acceptable behaviors at some point before the behaviors became addictive. Like cigarette smokers, these individuals will ignore or reject messages that do not address their concerns and interests; messages that do not acknowledge their perceived utility of the behavior; messages that are not relevant. As with the members of the Smokers Group, people who currently participate in harmful, risk-taking behavior are the very ones 
who may offer the most relevant messages for those who are at-risk for experimenting or adopting the same behavior.

Future research should continue to explore the construction and impact of personally relevant persuasive messages, especially those concerning socially important and intimate issues. Such research would benefit most from dialogue with members of the population these messages hope to influence. In the end, the contribution made by this line of research might be nothing less than helping people choose attitudes and behaviors that enhance, rather than endanger, their lives and their world. 
82

REFERENCES 


\section{REFERENCES}

Ajzen, I. \& Fishbein, M. (1977). Attitude-behavior relations: A theoretical analysis and review of empirical research. Psychological Bulletin, $\underline{84}$, 888-918.

Amos, A., \& Chollat-Tarquet, C. (1990, April-May). Women and tobacco. World Health, pp. 7-8.

Atkin, C. K., \& Freimuth, V. (1989). Formative evaluation research in campaign design. In R. E. Rice \& C. K. Atkin (Eds.), Public comminication campaigns (2nd ed., pp. 131-150). Newbury Park, CA: Sage.

Baker, S. \& Sherman, C. (1991, June). Saving your lungs and your life. Health, pp. 63-69.

Berscheid, E. (1966). Opinion change and communicator-communicatee similarity and dissimilarity. Journal of Personality and Social Psychology, 4, 670-680.

Brock, T. C. (1965). Communicator-recipient similarity and decision change. Journal of Personality and Social Psychology, 1, 650-654.

Burke, J.A., Salazar, A., Daugherty, V., \& Becker, S.L. (1989, November). Activating interpersonal influence in health promotion: A field test of Iowa's program against smoking. Paper presented at the meeting of the Speech Communication Association, San Francisco, CA.

Burnkrant, R. E., \& Unnava, H. R. (1989). Self-referencing: A strategy for increasing processing of message content. Personality and Social Psychology Bulletin, 15, 628-638.

Chaiken, S. (1980). Heuristic versus systematic information processing and the use of source versus message cues in persuasion. Journal of Personality and Social Psychology, 39, 752-766.

Fackelmann, K. A. (1991, April 6). Virus-smoking synergy causes malignancy. Science News, p. 215.

Fishbein, M. \& Ajzen, I. (1975). Belief, attitude intention, and behavior: An introduction to theory and research. Reading, MA: Addison-Wesley.

Federal survey counts female smokers. (1991, November 9). Science News, p. 302. 
Gilchrist, L. D., Schinke, S. P., \& Nurius, P. (1989). Reducing onset of habitual smoking among women. Preventive Medicine, 18, 235-248.

Glynn, T. J. (1989). Essential elements of school-based smoking prevention programs. Journal of School Health, 59, 181-188.

Glynn, K., Leventhal, H., \& Hirschman, R. (1985). A cognitive developmental approach to smoking prevention. In C. S. Bell \& R. Battjes (Eds.), Prevention research: Deterring drug abuse among children and adolescents. NIDA Research Monograph No. 63, 130-152. Washington, DC: U.S. Government Printing Office.

Haas, R. G. (1981). Effects of source characteristics on cognitive responses and persuasion. In R. E. Petty, T. M. Ostrom, \& T. C. Brock (Eds.), Cognitive responses in persuasion (pp. 141-172). Hillsdale, NJ: Lawrence Erlbaum.

Harris, J. (1984). Lung cancer among women. Journal of the American Medical Association, 252, 2806-2811.

Homer, P. M. \& Kahle, L. R. (1990). Source expertise, time of source identification, and involvement in persuasion: An elaborative processing perspective. Journal of Advertising, 19, 30-39.

Johnson, B. T. \& Eagly, A. H. (1989). Effects of involvement on persuasion: A meta-analysis. Psychological Bulletin, 106, 290-314.

Kardes, F. R. (1988). Spontaneous inference processes in advertising: The effects of conclusion omission and involvement on persuasion. Journal of Consumer Research, 15, 225-233.

Kerlinger, F. N. (1973). Foundations of behavioral research. (2nd ed.) New York: Holt, Rinehart and Winston.

Leippe, M. R., \& Elkin, R. A. (1987). When motives clash: Issue involvement and response involvement as determinants of persuasion. Journal of Personality and Social Psychology, 52, 269-278.

Leventhal, H. \& Cleary, P. D. (1980). The smoking problem: A review of the research and theory in behavioral risk wodification. Psychological Bulletin, 88, 370-405.

McGuire, W. J. (1969). The nature of attitudes and attitude change. In G. Lindzey \& E. Aronson (Eds.), The handbook of social psychology (2nd ed. Vol. 3). The individual in a social context (pp. 136-314). Reading, MA: Addison-Wesley. 
Norusis, M. J. (1988). SPSS:Data Entry II. Chicago: SPSS.

Norusis, M. J. (1988). SPSS/PC+V2,0 Base Manual. Chicago: SPSS.

Ostrom, T. M. \& Brock, T. C. (1968). A cognitive model of attitudinal involvement. In R. Abelson, E. Aronson, W. McGuire, T. Newcomb, M. Rosenberg, \& P. Tannenbaum (Eds.), Theories of cognitive consistency: A sourcebook (pp. 373-383). Chicago: Rand McNally.

Petty, R. E., \& Cacioppo, J. T. (1979) Issue involvement can increase or decrease persuasion by enhancing message-relevant cognitive responses. Journal of Personality and Social Psychology, 37, 1915-1926.

Petty, R. E., \& Cacioppo, J. T. (1984). The effects of involvement on responses to argument quantity and quality: Central and peripheral routes to persuasion. Journal of Personality and Social Psychology, 46, 69-81.

Petty, R. E., \& Cacioppo, J. T. (1986). Communication and persuasion: Central and peripheral routes to attitude change. New York: Springer-Verlag.

Petty, R. E., \& Cacioppo, J. T. (1990). Involvement and persuasion: Tradition versus integration. Psychological Bulletin, 107, 367-374.

Petty, R. E., Cacioppo, J. T., \& Schumann, D. (1983). Central and peripheral routes to advertising effectiveness: The moderating role of involvement. Journal of Consumer Research, 10, 135-146.

Sereno, K. K. (1968). Ego-involvement, high source credibility, and response to a belief-discrepant communication. Speech Monographs, 35, 476-481.

Sherif, C. W., Kelly, M., Rodgers, H. L., Jr., Sarup, G., \& Tittler, B. I. (1973). Personal involvement, social judgment, and action. Journal of Personality and Social Psychology 27, 311-328.

Sherif, M., \& Hovland, C. I. (1961). Social judgment: Assimilation and contrast effects in communication and attitude change. New Haven, CT: Yale University Press.

Smoking boosts risk of tubal pregnancy. (1991, March 16). Science News, p. 175.

Snyder, M., \& D€Bono, K. G. (1985). Appeals to image and claims about quality: Understanding the psychology of advertising. Journal of Personality and Social Psychology, 49, 586-697. 
Sorrentino, R. M., Bobocel, D. R., Gitta, M. Z., Olson, J. M., \& Hewitt, E. C. (1988). Uncertainty orientation and persuasion: Individual differences in the effects of personal relevance on social judgments. Journal of Personality and Social Psychology, 55, 357-371.

Stolley, P. D. (1983). Lung cancer in women: Five years later, situation worse. New England Journal of Medicine, 309, 428-429.

U.S. Department of Health and Human Services. (1989). Reducing the health consequences of smoking: 25 years of progress: A report of the Surgeon General. Publication No. CDC 89-8411. Washington, DC: U.S. Government Printing Office.

U.S. Public Health Service. (1980) The Health Consequences of Smoking for Women: A Report of the Surgeon General. Publication No. 0-326-003, 286 Washington, DC: U.S. Government Printing Office.

Zimbardo, P. (1960). Involvement and communication discrepancy as determinants of opinion conformity. Journal of Abnormal and Social Psychology, 60, 86-94. 


\section{APPENDIXES}


APPENDIX A

Questionnaire for High School Production Group Participants 
We at San Jose State are interested in your experience with cigarette smoking and how you feel about smoking and people who smoke.

All answers will be iept completely confidential.

Bex (M or F)__ Age___ Grade (9th, 10th, 11th, 12th)

Ethnic background: Afro-American__ American Indian

Cambodian Chinese __ Euro-Amerclan Fulipino

Elspanic Indian Eorean Vietnamese

Other. (please specify)

English is my native language second language

Have you ever tried clgarette smoking? Yes No

Do you smoke cigarettes now? Yes No

If any of the following questions do not apply to you, please put NA (not applicable)

How old were you when you smoked your first cigarette?

Who was with you when you smoked your first cigarette?

a friend a sister or brother alone other (who?)

How soon after your first cigarette smoking experience did you gmoke a cigarette again? a day a few days_ few weeks a few months

Who was with you this second time you smoked cigarettes?

a friend Q sister or brother alone other (who?)

Why do you think you flrst thed smoking a clgarette?

Why do you think you started smoking regularly? 


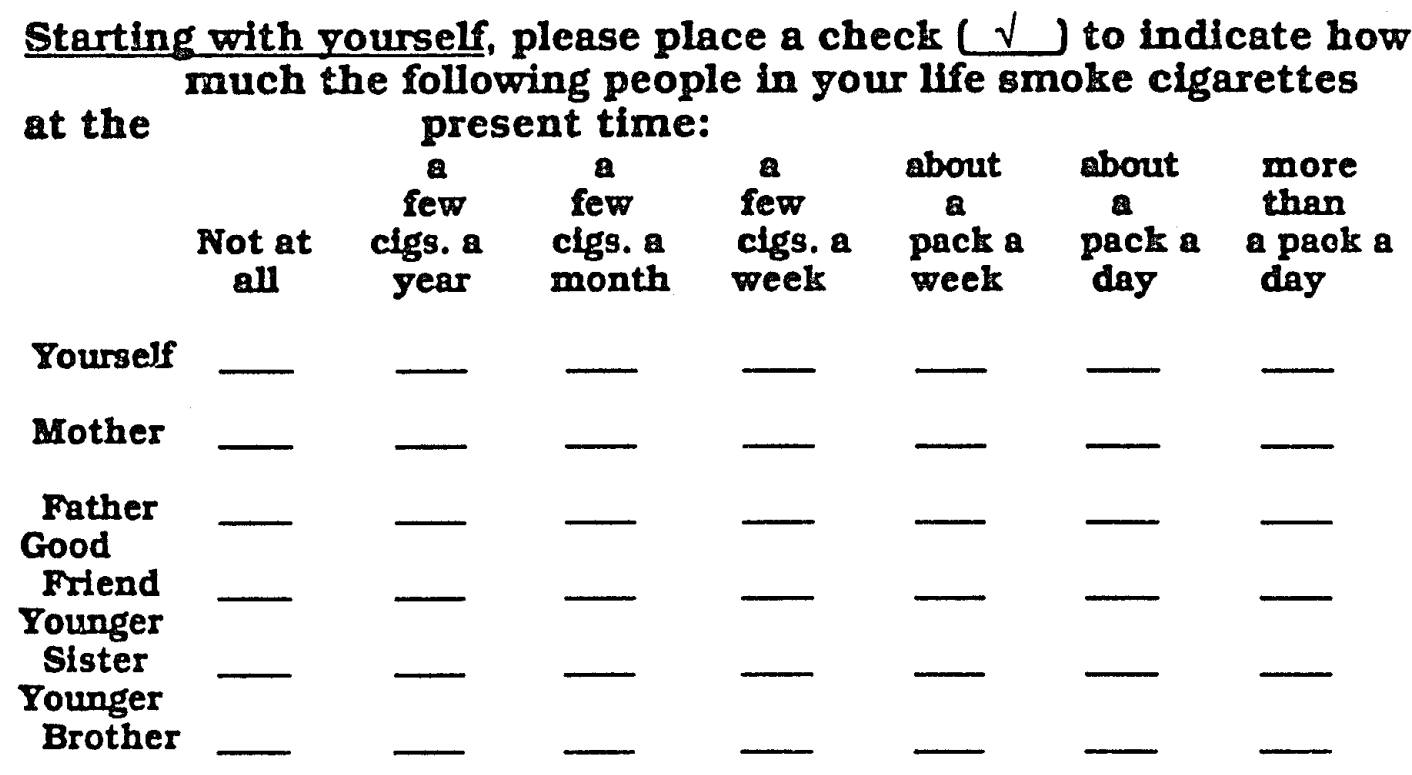

For each of the following statements. please circle the number that best describes your feeling about the statement, for example:

Cigarette smoking should be allowed in school.

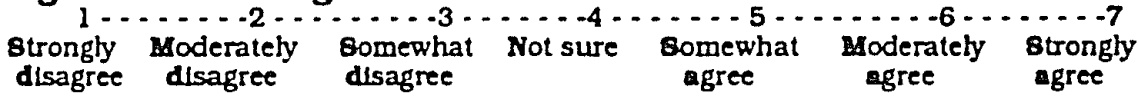

A circle around the 6 would mean that you moderately agree that cigarette smoking should be allowed in school.

Now, how do you feel about these statements? (circle a number)

\section{Back when I first started smoking cigarettes regularly,}

... It made me feel good (relared or energized).

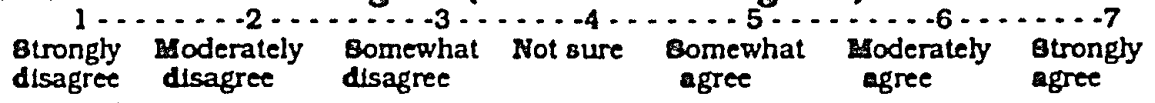

... It made me feel more like an adult (or more mature).

Btrongly Moderately $\begin{aligned} & \text { Somewhat Not sure } \\ & \text { disagree } \\ & \text { disagree }\end{aligned}$ agree
disagree

... It made me feel like part of a group.

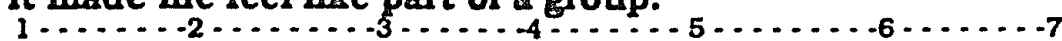

Btrongly Boderately Bomewhat Not Bure Bomewhat Soderately stronghy disagree disagree disagree agree agree agree 
Now, whenever I smoke cigarettes.

... It makes me feel good (relaxed or energized).

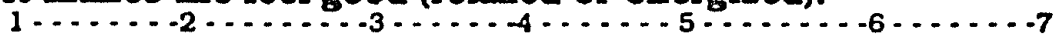

Btrongly Moderately Bomewhat Not sure Bomewhat Moderately Btrongly

disagree disagree disagree agree agree egree

. . It makes me feel more lke an adult (or more mature).

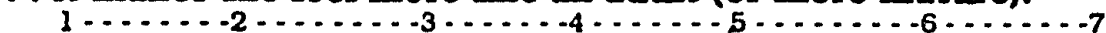

8trongly Moderately Bomewhat Not sure Bomewhat Moderately Btrongly

disagree disagree disagree agree agree agree

... It makes me feel like part of a group.

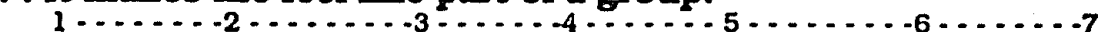

8trongly Moderately 8omewhat Not sure Bomewhat Moderately Btrongly

disagree disagree disagree agree agree agree

Now I would like you to give me your most CREATIVE Ideas!

If you were asked to make a television commercial to try to discourage a girl in Junior High School from smoking (say it was a younger sister, a friend of yours, or even a friend's younger gister), what would you talk about or show?

Your help on this project really means alot. Remember, your answers to these questions will be kept in strict confidence. No one except me and my advisor at San Jose State will know who gave what answers to which questions. Thanks for your help! 
APPENDIX B

Scripts ior Smokers Group and Nonsmokers Group PSAs 


\section{Smokers Group PSA (PSA \#2)}

60 seconds

The PSA opens with a scene showing four girls, apparently in their mid-teens, sitting in a circle in a park, music playing softly in the background. They are smoking cigarettes and, as one lights a cigarette, they engage in a discussion.

Girl 1: You know what guys? I really wish I could quit smoking.

Girl 2: Can you guys imagine not having to have that first cigarette when you wake up?

Girl 3: Imagine not having to depend on anything but yourself.

Girl 4: You know, when I first started smoking, I never thought I'd be addicted now.

Girl 1: And, you know, at school, I always feel like people look at me differently because I smoke.

Girl 2: Yeah, have you guys ever noticed that people stereotype us as drug users just because we smoke?

Girl 4: And I always feel so paranoid, hiding it from my parents.

Girl 3: If there's all these reasons why we shouldn't smoke, why the Hell can't we stop?

Each girl throws her cigarette away. (end of PSA) 


\section{Nonsmokers Group PSA (PSA \#2)}

30 seconds

The PSA begins with a close-up shot of the tail pipe of a starting car, exhaust smoke pouring out. The next shot is an extreme close up of a girl's face, showing only the nose and mouth area, and her fingers bringing a lit cigarette up to her mouth. She is taking drags on the cigarette, inhaling and blowing smoke out through her mouth. The shot of the exhaust pipe spewing smoke is seen again, followed again by the close up of the girl inhaling and exhaling smoke.

A medium close up is then shown of the girl, who appears to be between 14 and 18 years old, leaning against a tree, smoking a cigarette. She looks into the camera and says:

"Hey everybody. Let's stop polluting the environment so we can all live a long and healthy life."

This scene fades to black, and is followed by white words on a black screen. The first words that appear are,

"Why pollute the environment?"

These words are joined on the black screen by the words,

"Why pollute your health?"

All of these words disappear and are replaced by the words, in all capital letters, "WHY SMOKE?"

These words then fade to black. (end of PSA) 